University of Michigan Law School

University of Michigan Law School Scholarship Repository

Law \& Economics Working Papers

$9-1-2020$

\title{
Class Actions and Private Antitrust Litigation
}

\author{
Albert H. Choi \\ University of Michigan Law School, alchoi@umich.edu \\ Kathryn E. Sprier \\ Harvard University Law School
}

Follow this and additional works at: https://repository.law.umich.edu/law_econ_current

Part of the Antitrust and Trade Regulation Commons, Commercial Law Commons, Contracts Commons, Law and Economics Commons, and the Litigation Commons

Working Paper Citation

Choi, Albert H. and Sprier, Kathryn E., "Class Actions and Private Antitrust Litigation" (2020). Law \& Economics Working Papers. 180.

https://repository.law.umich.edu/law_econ_current/180

This Article is brought to you for free and open access by University of Michigan Law School Scholarship Repository. It has been accepted for inclusion in Law \& Economics Working Papers by an authorized administrator of University of Michigan Law School Scholarship Repository. For more information, please contact mlaw.repository@umich.edu. 


\title{
Class Actions and Private Antitrust Litigation
}

\author{
Albert H. Choi \\ University of Michigan Law School \\ Kathryn E. Spier* \\ Harvard Law School
}

September 1, 2020

\begin{abstract}
When firms collude and charge supracompetitive prices, consumers can bring antitrust lawsuits against the firms. When the litigation cost is low, firms accept the cost as just another cost of doing business, whereas when the cost is high, the firms lower the price to deter litigation. Class action is modeled as a mechanism that allows plaintiffs and attorneys to obtain economies of scale. We show that class actions, and the firms' incentive to block them, may or may not be socially desirable. Agency problems, settlement, fee-shifting, treble damages, public enforcement, and sustaining collusion through repeat play are also considered.
\end{abstract}

JEL Codes: D21, K12, K21, K41, L41

*alchoi@umich.edu and kspier@law.harvard.edu. We would like to thank the editor and two anonymous referees, Maureen Carroll, Daniel Crane, Andy Daughety, Frank Easterbrook, Richard Holden, Louis Kaplow, Rohan Pitchford, Jennifer Reinganum, Sarath Sanga, Martin Schmalz, Danny Sokol, and Abe Wickelgren, and the participants of various seminars and conferences for many helpful comments and suggestions. 


\section{Introduction}

In the United States, victims of corporate misconduct and unlawful business practices can sometimes consolidate their individual lawsuits into a single class action, so as to achieve economies of scale and other benefits. ${ }^{1}$ Examples of successful class action litigation include products liability lawsuits, pricing fixing and other antitrust lawsuits, lawsuits by employees against an employer alleging discrimination, and securities class actions by public investors. Traditionally, the U.S. legal system was quite hospitable to class actions. In 1980, for instance, the U.S. Supreme Court extolled the class-action mechanism, stating that "aggrieved persons may be without any effective redress unless they may employ the class-action device." ${ }^{2}$ With the endorsement of the U.S. Supreme Court, class actions flourished in the United States.

Recently, however, the class-action mechanism has been under attack. Most importantly, the U.S. Supreme Court tightened the requirements for class certification through cases, such as Wal-Mart Stores, Inc. v. Dukes and Comcast Corp. v. Behrend, significantly raising the barriers against new class actions. ${ }^{3}$ Furthermore, businesses increasingly deflect class actions by requiring consumers, suppliers, and employees to waive their rights to bring class actions. When purchasing a cell phone plan, for example, consumers are required to sign away their right to litigate and agree to channel their complaints through individual arbitration. ${ }^{4}$ In a series of landmark rulings, including Concepcion, Italian Colors, and Epic Systems, the U.S. Supreme Court upheld private contracts that block class actions. ${ }^{5}$

This paper analyzes the private and social desirability of class action lawsuits

\footnotetext{
${ }^{1}$ See for example Dam (1975), Miller (1998), Bone (2012), and Rosenberg and Spier (2014). Notwithstanding the possible benefits, the class action has always been controversial. Many scholars and practitioners have argued that the system is inefficient and engenders a new type of agency problem, that between plaintiffs and their representative lawyers.

${ }^{2}$ See Deposit Guar. Nat'l Bank v. Roper, 445 U.S. 326, 339 (1980). Rule 23 of the Federal Rules of Civil Procedure, in its modern form, was adopted in 1966 and allows lawsuits to be brought on behalf of a class of victims who have allegedly suffered harm.

${ }^{3}$ See Wal-Mart Stores, Inc. v. Dukes, 564 U.S. 338 (2011), and Comcast Corp. v. Behrend, 569 U.S. 27 (2013).

${ }^{4}$ These contractual arrangements have proliferated recently. See Gilles (2005), Resnik (2015), and Choi and Spier (2021). A recent federal bill, The Fairness in Class Action Litigation Act of 2017 (FICLA), is also viewed as being hostile to class actions.

${ }^{5}$ See AT6T Mobility LLC v. Concepcion, 563 U.S. 333 (2011), American Express Co. v. Italian Colors Rest., 133 S. Ct. 2304 (2013), and Epic Systems Corp. v. Lewis, 138 S. Ct. 1612 (2018). In 2017, the Consumer Financial Protection Bureau (CFPB) issued the Arbitration Agreements Rule prohibiting mandatory arbitration clauses in consumer financial contracts but the rule was overturned by Congress in a 51-50 vote. See Ackerman and Hayashi (2017). There is also debate about whether a firm undertaking IPOs may impose a mandatory arbitration clause in its charter or bylaws. See Aggarwal, Choi, and Eldar (2020).
} 
in the context of private antitrust litigation. ${ }^{6}$ We focus on possible price fixing by firm-defendants in a market, and the class action is modeled as a mechanism that allows consumer-plaintiffs and their attorneys to lower their cost of bringing lawsuits against the firm-defendants. Our analysis produces several results. Importantly, the analysis shows that class action lawsuits may or may not be socially desirable. In some circumstances, the threat of class actions may force the firms to lower their prices to avoid lawsuits. But if the class action mechanism makes lawsuits sufficiently cheap and easy to bring, firms may simply accept litigation as a necessary cost of business and engage in even more egregious anti-competitive conduct. We show that, depending on the circumstances, the firms' private incentive to block class action lawsuits may be socially excessive or socially insufficient.

We begin with a simple model where firm-defendants collude to fix their prices in the shadow of future litigation. A higher price-cost markup raises the level of damages that the consumers can collect, in case the firms are found guilty of price fixing. We parameterize the degree to which consumers are forward-looking and anticipate being plaintiffs in future antitrust litigation. Fully forward-looking consumers have rational expectations and understand that they may receive damage payments from the firms in the future. These sophisticated consumers view the expected damage payments as a rebate that partially offsets the purchase price of the product. Fully myopic consumers, on the other hand, do not foresee being plaintiffs in the future, and focus only on the sticker price when deciding whether or not to purchase the product.

The most profitable strategy for the colluding firms depends on the consumers' cost of bringing private antitrust lawsuits and on the degree of consumer myopia. We analyze the firms' pricing strategies for three different regions of litigation costs: a high-cost region where the firms engage in unbridled collusion and lawsuits never arise, an intermediate-cost region where the threat of litigation disciplines the market price, and a low-cost region where firms collude and endure lawsuits in equilibrium. For each region we perform local comparative statics to see how lowering the consumerplaintiffs' costs of bringing lawsuits and the degree of consumer myopia affect prices, profits, consumer surplus and social welfare. We also examine the (potentially discontinuous) changes in welfare when costs move across regions.

First, when the consumers' cost of bringing lawsuits is above a threshold, the firms are effectively immune from litigation. Since consumers face high barriers to bringing lawsuits against the firms, the firms will collude and fix their prices at unconstrained

\footnotetext{
${ }^{6}$ Between 1975 and 2012, 92\% of all antitrust lawsuits filed in U.S. District courts were brought by private parties rather than by government agencies. See Sourcebook of Criminal Justice Statistics Online, www.albany.edu/sourcebook/tost5.html. See also Crane (2011). Private antitrust litigation may be a substitute or a complement for public enforcement. Kauper and Snyder (1985) find in their sample of 1,938 private antitrust cases that $91 \%$ were initiated independently of government cases and $9 \%$ were follow-on cases.
} 
monopoly levels. From the firms' perspective, this is the ideal outcome. From the perspective of consumers and the social planner, this is suboptimal. Consumers must pay a high price for the products, and the market suffers the conventional deadweight loss from restricted supply. Given that there is no litigation in equilibrium, though, there is no deadweight loss from litigation.

Second, when the consumers' cost of bringing suit is in an intermediate region, the firms will deter lawsuits by setting the price below the monopoly level. Had the firms charged the unconstrained monopoly price, the consumers would have filed antitrust lawsuits, and resources would be spent on litigation. In this intermediate case, the firms lower the market price to just below the point where the consumers are indifferent between bringing suit and not bringing suit. Note that when the consumers' cost of bringing suit falls, the market price must fall too. The lower market price harms the firms' profits, but increases consumer surplus and benefits society more broadly (the deadweight loss shrinks).

Third, when the consumers' cost of bringing private antitrust lawsuits is in a low region, the colluding firms will choose to accommodate lawsuits. Instead of deterring lawsuits by charging a very low price, the colluding firms will instead raise their prices to (modified) monopoly levels. Here, the colluding firms make a conscious decision to accept the costs of litigation as simply another cost of doing business. In this low region, the firms and the consumers are better off when, on the margin, it is cheaper for consumers to bring private antitrust lawsuits. Lower costs correspond to lower prices for the consumers and higher profits for the firms. We show that firms are better off when consumers are forward looking, but consumers may be worse off. If consumers are myopic and do not foresee being plaintiffs in future litigation, the firms may set lower prices to stimulate demand.

Next, we adapt the benchmark model to explore the implications of class action lawsuits. We focus on two salient effects. First, class actions allow the consumerplaintiffs to achieve economies of scale and lower the costs of litigation. Second, class actions create a separation of ownership and control of the litigation, and may allow the lawyers and other third parties to capture the value from litigation. We explore the firms' private incentives to block class action lawsuits by requiring consumer to sign class action waivers as a condition of purchase, and the social welfare implications.

Our analysis shows that the firms' private incentives to block class action lawsuits may be either aligned with the social incentives, socially excessive, or socially insufficient. The fact that the firms may have a socially excessive incentive to block class actions is not surprising. Imagine that when class actions are blocked, the firms are effectively immune from litigation (because the cost of bringing an individual lawsuit is very high). Then, the firms can engage in unbridled collusion. If class actions allow the consumer-plaintiffs and their attorneys to achieve economies of scale, and (importantly) if the cost of bringing a class action lawsuit is in the intermediate region, 
class actions have a valuable deterrent effect. The threat of class action litigation forces the firms to lower their prices, and consumer surplus and social welfare rise.

In other settings, the firms' private decision to block class actions is socially desirable. Suppose, as above, that, when class actions are blocked, the firms are effectively immune from litigation. Suppose further that the economies of scale from class actions are very strong, so the cost of bringing a class action lawsuit is in the low region. In such a scenario, class actions do not deter the firms from colluding on price. ${ }^{7}$ Instead, the firms will raise their prices above the standard monopoly level to account for the costs of litigation, creating a larger deadweight loss. The deadweight loss may be larger if lawyers and third parties capture the litigation surplus. For these reasons, the consumers are better off blocking class actions, too. ${ }^{8}$

Finally, there are settings where firms allow class actions but consumers and society would be better off if class actions were blocked. To illustrate how this can happen, suppose that the cost of bringing an individual lawsuit is in the intermediate region. Then, the threat of individual litigation has a deterrent effect and the firms reduce their prices to avoid litigation. Suppose further that the cost of bringing a class action is in the low region. Class actions do not deter collusion in this case. The firms will embrace litigation and set their prices at even higher level, reducing consumer surplus and increasing the deadweight loss. When the scale economies are very strong, the firms' incentive to allow class actions may be socially excessive or, equivalently, their incentives to block class actions socially insufficient.

We also extend the basic analysis in several directions. First, our main analysis assumes that all lawsuits go to trial. We show that in a world of frictionless settlement, whether the firms will allow credible lawsuits in equilibrium depends on the degree of consumers' myopia. If the consumers are fully forward-looking, for instance, the firms can obtain the unconstrained monopoly profit regardless of the consumers' litigation cost. If the consumers are (partially) myopic, on the other hand, the firms may choose a price below the full-monopoly level to deter lawsuits and keep settlement off the equilibrium path. Other variations, such as fee-shifting rules, damage multipliers, interactions with public enforcement, and sustaining collusion through repeat play, are also examined.

Our model is related to the literature on the real effects of treble damages in private antitrust litigation. Breit and Elzinga (1974) and Easterbrook (1985) have argued that far-sighted consumers will take into account future damage awards when making their purchase decisions. ${ }^{9}$ In models with costless litigation, Salant (1987) and Baker

\footnotetext{
${ }^{7}$ To deter lawsuits, the firms would need to lower their prices dramatically.

${ }^{8}$ Interestingly, it is not socially desirable for the cost of litigation to be too small. We prove that social welfare is highest when the consumer's cost of bringing suit is at the very bottom of the intermediate-cost region.

${ }^{9}$ Easterbrook $(1985,451)$ notes that if consumers "have perfect information and enforcement is
} 
(1988) show formally how damage remedies (even treble damages) can have neutral welfare consequences and no deterrent effect. Besanko and Spulber (1990) show that this neutrality does not hold when the firms have private information about the cost of production and expected damages are under-compensatory (an assumption that we will relax). None of these papers fully characterize the equilibrium pricing and settlement strategies with costly litigation, explore the comparative statics, or derive the welfare implications with respect to class actions and class action waivers. ${ }^{10}$

The paper is organized as follows. Section 2 presents the basic setup of the model, characterizes the equilibrium, and presents basic comparative statics results. Section 3 explores the positive and normative implications of class actions, paying particular attention to the economies scale in litigation and rent extraction by lawyers and third parties. Section 4 extends the basic model to include out-of-court settlement, the shifting of legal fees to the loser, damage multipliers, public enforcement, and repeat play. Proofs may be found in Appendix A.

\section{The Model}

Suppose there is a unit mass of consumers. Each consumer demands at most one unit of the good and has valuation $v \in[0, \bar{v}]$. The valuations are distributed according to a strictly positive and differentiable probability density function $f(\cdot)$ and corresponding cumulative density function $F(\cdot)$. Conditional on equilibrium price $p$, the aggregate demand is given by

$$
D(p)=\int_{p}^{\bar{v}} f(v) d v .
$$

There are $N>1$ firms in the market with the identical, constant marginal cost of $c \in[0, \bar{v})$. Both the number of firms $(N)$ and the constant marginal cost $(c)$ are common knowledge. Firms sell homogeneous products. Consumers costlessly observe all posted prices and other non-price terms (such as a class action waiver) in the market before deciding whether (and from whom) to purchase.

We now define some important notation. If the equilibrium market price is $p$ then the aggregate industry profit is given by

$$
\Pi(p, c)=\int_{p}^{\bar{v}}(p-c) f(v) d v=D(p)(p-c) .
$$

costless, they view the future recovery as a cents-off coupon attached to each purchase."

${ }^{10}$ Spulber $(1989,592)$ briefly discusses litigation costs and how firms may choose to either allow or prevent litigation. 
Without any collusion, we assume that the firms compete head-to-head, charge $p=c$, and earn zero profits. ${ }^{11}$ With perfect collusion (and with no liability), on the other hand, the firms would agree to set the price at the monopoly level:

$$
p^{m}(c)=\arg \max \Pi(p, c) .
$$

For ease of analysis, we assume that the profit function is strictly concave in price and therefore $p^{m}(c)$ is unique. Finally, social welfare is

$$
W(p, c)=\int_{p}^{\bar{v}}(v-c) f(v) d v .
$$

From the social welfare function, the first-best outcome is obtained (i.e., social welfare is maximized) when $p=c$.

Suppose that there are antitrust laws that allow consumers to bring lawsuits when the market price is above marginal cost, $p>c .{ }^{12}$ Consumers who have purchased the product can then sue the firms to collect damages $d=\theta(p-c)$ where $\theta \in(0,1)$. There are different interpretations of the parameter $\theta$. It could simply be the probability that the plaintiffs will successfully present evidence of collusion. Alternatively, $\theta<1$ could reflect court error or a pro-defendant bias where the court gives a "haircut" of $1-\theta$ to the actual overcharge. By tweaking notation, it could also reflect a biased assessment by the court of the firm-defendants' marginal costs. Note that since $\theta<1$, the expected damage award is not fully compensatory. We will see shortly that the assumption also implies that the firms are not completely deterred from colluding on price. $^{13}$

Litigation is expensive for both the consumers and the firms. The litigation costs per unit sold are $k_{p}>0$ for the consumers (the plaintiffs) and $k_{d}>0$ for the firms (the defendants). We let $k=k_{p}+k_{d}$ and assume that $c+k<\bar{v}{ }^{14}$ Given the positive litigation cost, consumers will bring suit if and only if it is profitable to do

\footnotetext{
${ }^{11}$ This is the unique symmetric Nash equilibrium of the static pricing game. If $N>2$, there are payoff-equivalent non-symmetric equilibria of the static game where, for example, some firms charge $p>c$ and have zero sales. The allocation of consumers is irrelevant in this environment.

${ }^{12}$ For now, we restrict attention to private antitrust litigation. It is estimated that there are ten private antitrust lawsuits for every one government suit. See Crane (2011). Lande and Davis (2007) find in a sample of large antitrust actions that $\$ 18$ billion were paid in private damages and $\$ 4$ billion in criminal penalties. The gap remains significant even when prison sentences are taken into account. In Section 4.4, we examine how also allowing public enforcement affects the main results.

${ }^{13}$ In Section 3.2, we analyze the possibility that third parties (for instance, class action lawyers or frivolous plaintiffs) capture surplus from litigation. Section 4.3 extends the analysis to allow $\theta \geq 1$, e.g. through supra-compensatory damages.

${ }^{14}$ This condition implies that the product would be sold even if all consumers bring lawsuits. We assume that $k_{p}$ and $k_{d}$ reflect real economic costs rather than attorney rents. Attorney rent-seeking is explored in Section 3.2.
} 
so: $\theta(p-c)-k_{p}>0$. When indifferent, $\theta(p-c)-k_{p}=0$, we assume that consumers do not bring suit. ${ }^{15}$

We let $\mu \in[0,1]$ parameterize the degree to which consumers anticipate being plaintiffs in litigation. When $\mu=0$, the consumers are myopic and do not expect to benefit from litigation in the future. In this case, any litigation surplus will accrue to the consumers' future selves. When $\mu=1$, the consumers are fully forward-looking: they apply higher-level reasoning and can foresee being plaintiffs in ex post litigation. When $\mu=1$, consumers will treat any future damage award, minus the litigation cost, as an expected rebate when making their purchase decisions. ${ }^{16}$ In general, a consumer will purchase the product if their valuation for the product exceeds the perceived net price, $v \geq p-\mu \times \max \left\{\theta(p-c)-k_{p}, 0\right\}$. In contrast to the consumers, we assume that the firms have rational expectations about future litigation.

The timing of the game is as follows. At $t=1$, the $N$ firms offer to sell homogeneous products at price, $p$, and with or without a class action waiver. We implicitly assume that the firms are acting in their joint interest, and have mechanisms to enforce their collusive agreement. ${ }^{17}$ At $t=2$, the consumers decide whether to purchase the product. After purchasing the product, at $t=3$, consumers decide whether to bring suit to collect damages for any overcharges. If lawsuits are brought, the perunit litigation costs are borne and per-unit damages $d=\theta(p-c)$ are paid at $t=4$. For simplicity, there is no time discounting. The solution concept is subgame-perfect Nash equilibrium.

\subsection{Preliminary Analysis}

We begin by characterizing the firm's profit function. If $p \leq c+k_{p} / \theta$, lawsuits have (weakly) negative expected value and the consumers do not bring suits ex post. A consumer will purchase the product if $v>p$, and the firms' aggregate profits are $\Pi(p, c)=D(p)(p-c)$. If $p>c+k_{p} / \theta$, lawsuits have positive expected value and the consumers will bring suits ex post, obtaining a net rebate of $\theta(p-c)-k_{p}$ per unit. A consumer will purchase the product when their valuation $v$ (weakly) exceeds the perceived effective price $x(p)$, where

$$
x(p)=p-\mu\left(\theta(p-c)-k_{p}\right)
$$

\footnotetext{
${ }^{15}$ Note that while each consumer places a different valuation on the product, each consumer's cost of litigation is the same. This assumption is made for simplicity.

${ }^{16}$ Alternatively, one can interpret $\mu$ as the consumer-plaintiff's discount factor, or the probability with which consumers expect to receive a rebate.

${ }^{17}$ They could accomplish this through repeated interaction if price deviations are observed and the discount factor is sufficiently high. See the repeat play extension in Section 4.5.
} 
If $p>c+k_{p} / \theta$, the aggregate demand is $D(x(p))$ and, taking into account the firms' litigation costs and damage payments, aggregate firm profits are

$$
D(x(p))\left[p-c-\left(\theta(p-c)+k_{d}\right)\right] .
$$

Rearranging this expression, and recalling that $k=k_{p}+k_{d}$, we have the following lemma.

Lemma 1. Aggregate firm profits are a piecewise continuous function of the price p:

$$
\begin{cases}\Pi(p, c) & \text { if } p \leq c+k_{p} / \theta \\ \Pi(x(p), c+k)-(1-\mu) D(x(p))\left[\theta(p-c)-k_{p}\right] & \text { if } p>c+k_{p} / \theta\end{cases}
$$

where $x(p)$ is defined in (4). Conditional on $p$, aggregate firm profits are weakly increasing in $\mu$.

The profit function in equation (6) is intuitive. Suppose $p>c+k_{p} / \theta$. If the consumers are completely forward-looking $(\mu=1)$, the firms' aggregate profits are simply $\Pi(x(p), c+k)$, the profits of a hypothetical firm with unit cost $c+k$. This makes sense. When $\mu=1$, then effective price paid by consumers is $x(p)=p-\left(\theta(p-c)-k_{p}\right)$ and the effective price received by the firms is $p-\theta(p-c)-k_{d}$. Using the litigation system to transfer $\theta(p-c)$ from the firms to the consumers is inefficient, as the parties jointly bear the cost of litigation $k=k_{p}+k_{d}$. So, the first term in the firm's aggregate profit function in $(6), \Pi(x(p), c+k)$, reflects both the production cost $c$ and the joint litigation cost $k$.

The second term in equation $(6),(1-\mu) D(x(p))\left[\theta(p-c)-k_{p}\right]$, is intuitive as well. This is the loss of firm profits stemming from the misperceptions of consumers. To understand why, recall that $\theta(p-c)-k_{p}$ is the consumers' net ex post rebate per unit sold. Consumers anticipate receiving fraction $\mu$ of this rebate at the time of purchase, but fraction $1-\mu$ is unanticipated. So, $(1-\mu) D(x(p))\left[\theta(p-c)-k_{p}\right]$ is an ex post windfall for the consumers. Thus, the second term from equation (6) quantifies the transfer of value from the firms to the myopic consumers.

Note that the firms' aggregate profits in equation (6) is a discontinuous function of the price, $p$. If the price is below the threshold, $p \leq c+k_{p} / \theta$, consumers do not bring lawsuits and the profit function reflects the production costs only, $\Pi(p, c)$. When the effective price is above the threshold, $p>c+k_{p} / \theta$, the consumers bring lawsuits ex post and the firms' profits drop. This happens for two distinct reasons. First, the profits fall because consumers bring lawsuits and litigation is costly. Second, when consumers are myopic and do not anticipate being plaintiffs in litigation, the consumers receive a windfall gain ex post so, as previously discussed, the firms suffer a corresponding loss. 
We now define some important new notation. Inverting $x(p)$ in (4) gives:

$$
p(x)=x+\left(\frac{\mu}{1-\mu \theta}\right)\left(\theta(x-c)-k_{p}\right)
$$

Define $\widehat{k}_{p}$ be the implicit solution to the following equation:

$$
\Pi\left(c+k_{p} / \theta, c\right)=\max _{x}\left\{\Pi\left(x, c+k_{p}+k_{d}\right)-(1-\mu) D(x)\left[\theta(p(x)-c)-k_{p}\right]\right\} .
$$

The left-hand side of (8) represents the firms' aggregate profits when $p=c+k_{p} / \theta$. No lawsuits are filed and consumers purchase the product if and only if $v \geq p=c+k_{p} / \theta$. The right-hand side of (8) represents the maximal profits for the firms when they charge an effective price $x$ (as perceived by consumers) and the consumers bring

lawsuits. The following lemma states that $\widehat{k}_{p}$ exists and is unique, and describes how $\widehat{k}_{p}$ depends on the parameter $\mu$.

Lemma 2. There exists a unique value $\widehat{k}_{p}(\mu) \in\left(0, \theta\left(p^{m}(c)-c\right)\right)$ that satisfies (8). As $\mu$ increases, $\widehat{k}_{p}$ increases: $\widehat{k}_{p}^{\prime}(\mu)>0$.

The definition of $\widehat{k}_{p}(\mu)$ in (8) is illustrated graphically in Figure 1 for the special case where consumers are fully forward-looking $(\mu=1)$. The effective price $x$ is on the horizontal axis. The upper parabola represents the firms' aggregate profits when there is no litigation, while the lower parabola represents the aggregate profits when there is litigation. As $k_{p}$ rises, the upper parabola remains fixed and the lower parabola shifts downwards. When $k_{p}=\widehat{k}_{p}$, the aggregate profits the firm can generate while bypassing litigation are the same as the maximum profits they can earn while allowing litigation (the peak of the lower parabola). More generally, if $\mu<1$, then the lower parabola in Figure 1 would shift downwards, representing the loss of profits from systematic consumer misperceptions about future litigation. The upper parabola, representing firm profits without litigation, would remain fixed. Thus, as indicated in Lemma 2, the threshold $\widehat{k}_{p}(\mu)$ is smaller when consumers are myopic $(\mu<1)$ and do not fully anticipate being plaintiffs in future litigation.

\subsection{Equilibrium Characterization}

The threshold plaintiff litigation cost $\widehat{k}_{p}(\mu)$ defined in Lemma 2 plays an important role in our analysis of the firms' pricing strategy. When $k_{p}<\widehat{k}_{p}(\mu)$, because the consumers' litigation cost is sufficiently low, the firms are better off allowing lawsuits in equilibrium. The firms will raise the effective price above the monopoly price $p^{m}(c)$ and the consumers will bring suit after purchasing the product. When $k_{p}$ rises and 


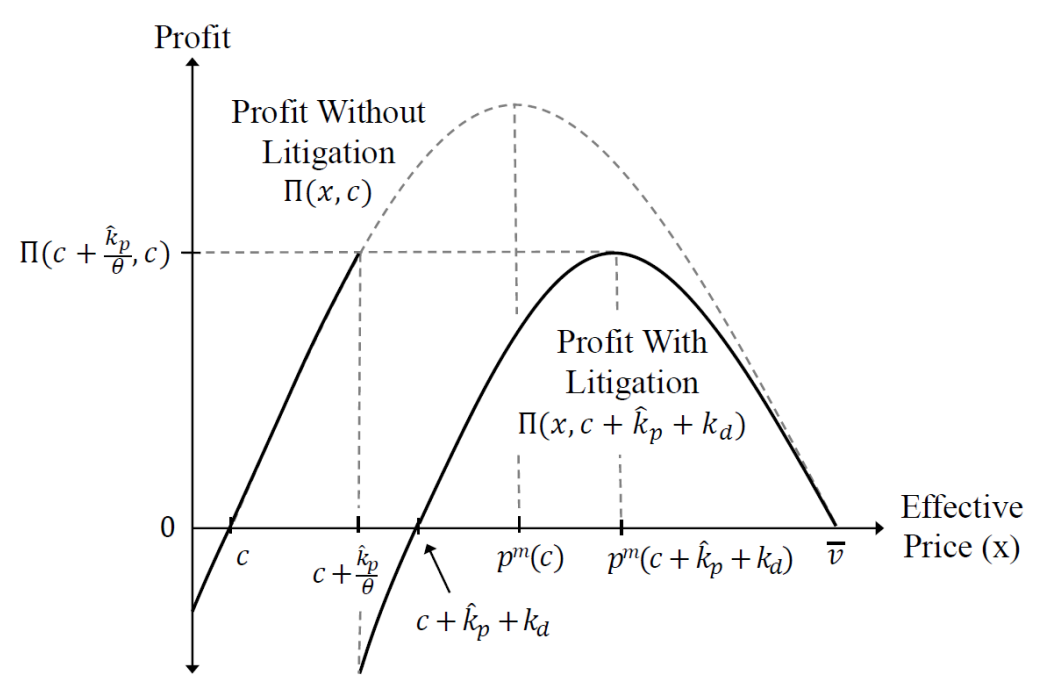

Figure 1: Definition of $\widehat{k}_{p}(\mu=1)$

crosses the threshold $\widehat{k}_{p}(\mu)$ from below, firms will lower the price to $p=c+k_{p} / \theta$ to deter lawsuits in equilibrium. When $k_{p}$ rises above $\theta\left(p^{m}(c)-c\right)$, the firms can charge the unconstrained monopoly price and enjoy immunity from litigation, as consumers would find it prohibitively expensive to pursue antitrust litigation. Proposition 1 describes the firms' pricing strategies, profits, and social welfare.

Proposition 1. The equilibrium prices, litigation decisions, firm profits, and social welfare depend on the plaintiffs' litigation costs $k_{p}$ and parameter $\mu$ as follows:

1. If $k_{p}<\widehat{k}_{p}(\mu)$, the effective price is $p^{m}(c+\widetilde{k})$ where $\widetilde{k}=\mu k_{p}+\left(\frac{1-\mu \theta}{1-\theta}\right) k_{d}$ and lawsuits are brought in equilibrium. ${ }^{18}$ Aggregate firm profits are $\left(\frac{1-\theta}{1-\mu \theta}\right) \Pi\left(p^{m}(c+\right.$ $\widetilde{k}), c+\widetilde{k})$ and social welfare is $W\left(p^{m}(c+\widetilde{k}), c+k\right)$. When $\mu \in(0,1]$, as $k_{p}$ increases, firm profits and social welfare strictly decrease. When $\mu=0$, as $k_{p}$ increases, firm profits stay the same and social welfare strictly decreases. As $\mu$ increases, firm profits increase and social welfare increases (decreases) if $\frac{k_{p}}{k_{d}}<(>) \frac{\theta}{1-\theta}$.

2. If $k_{p} \in\left[\widehat{k}_{p}(\mu), \theta\left(p^{m}(c)-c\right)\right)$, the price is $c+\frac{k_{p}}{\theta}$ and no lawsuits are brought in equilibrium. Aggregate firm profits are $\Pi\left(c+\frac{k_{p}}{\theta}, c\right)$ and social welfare is $W\left(c+\frac{k_{p}}{\theta}, c\right)$. As $k_{p}$ increases, firm profits increase and social welfare decreases. Neither firm profits nor social welfare depend on $\mu$.

\footnotetext{
${ }^{18}$ At the time of purchase, the consumer pays an actual price that is higher than $p^{m}(c+\widetilde{k})$ but receives a rebate ex post.
} 
3. If $k_{p} \geq \theta\left(p^{m}(c)-c\right)$, the price is $p^{m}(c)$ and no lawsuits are brought in equilibrium. Aggregate firm profits are $\Pi\left(p^{m}(c), c\right)$ and social welfare is $W\left(p^{m}(c), c\right)$. Neither firm profits nor social welfare depend on $k_{p}$ or $\mu$.

According to Proposition 1, when the consumers' litigation cost is below the threshold, $k_{p}<\widehat{k}_{p}(\mu)$, the colluding firms treat the future litigation costs and damage payments as just another cost of doing business, and set price accordingly. The effective price is $p^{m}(c+\widetilde{k})$ where $\widetilde{k}=\mu k_{p}+\left(\frac{1-\mu \theta}{1-\theta}\right) k_{d}>0$. The expression $\widetilde{k}$ can be thought of as the firms' total (direct and indirect) litigation cost born in equilibrium. In addition to the direct litigation cost of $k_{d}$, firms will also indirectly bear consumers' litigation cost of $k_{p}$, depending on how forward looking consumers are. For instance, when $\mu=1$, then $\widetilde{k}=k_{p}+k_{d}$ and the effective price paid by consumers is $p^{m}\left(c+k_{p}+k_{d}\right)$. With fully forward looking consumers, because the consumers take into account the litigation cost to the fullest extent and lower their willingness to pay in accordance, the firms get to fully (and indirectly) bear the consumers' litigation cost. When $\mu=0$, on the other hand, consumers treat the price at face value and so $\widetilde{k}=\frac{k_{d}}{1-\theta}$ and $p^{m}(c+\widetilde{k})$ do not depend on the consumer's litigation cost $k_{p} \cdot{ }^{19}$

When the consumers' litigation cost is in the middle range, $k_{p} \in\left[\widehat{k}_{p}(\mu), \theta\left(p^{m}(c)-\right.\right.$ $c)$ ), the firms find it worthwhile to set the price just low enough to deter lawsuits: $p=c+k_{p} / \theta$. Finally, when the consumer-plaintiffs' litigation cost is in the high region, $k_{p} \geq \theta\left(p^{m}(c)-c\right)$, the firms simply collude on the monopoly price of $p^{m}(c)$ and consumers will not sue since lawsuits are prohibitively expensive. The colluding firms are insulated from litigation in this case. The results from Proposition 1 are shown in Figure 2 for the special case where consumers are fully forward looking and expect to receive the full litigation surplus $(\mu=1)$ and in Figure 3 for the case where consumers are completely myopic $(\mu=0)$.

\subsection{Comparative Statics}

Proposition 1 describes how aggregate firm profits and social welfare depend on the plaintiff's litigation cost, $k_{p}$, and the consumer (mis)perceptions parameter $\mu$. In this subsection, we discuss these comparative statics results in more detail. In the first part, we examine how firm profits and social welfare change as $k_{p}$ changes and, in the second, we examine the impact of change in $\mu$.

\subsubsection{Litigation Costs}

When $k_{p}<\widehat{k}_{p}(\mu)$, in equilibrium, consumers file suit after purchasing the product. As illustrated in Figure 2 for the special case where consumers are fully forward looking

${ }^{19}$ When $\mu=0$, firm profits become $D(p)\left[(1-\theta)(p-c)-k_{d}\right]=(1-\theta) D(p)\left[p-c-\frac{k_{d}}{1-\theta}\right]$. 


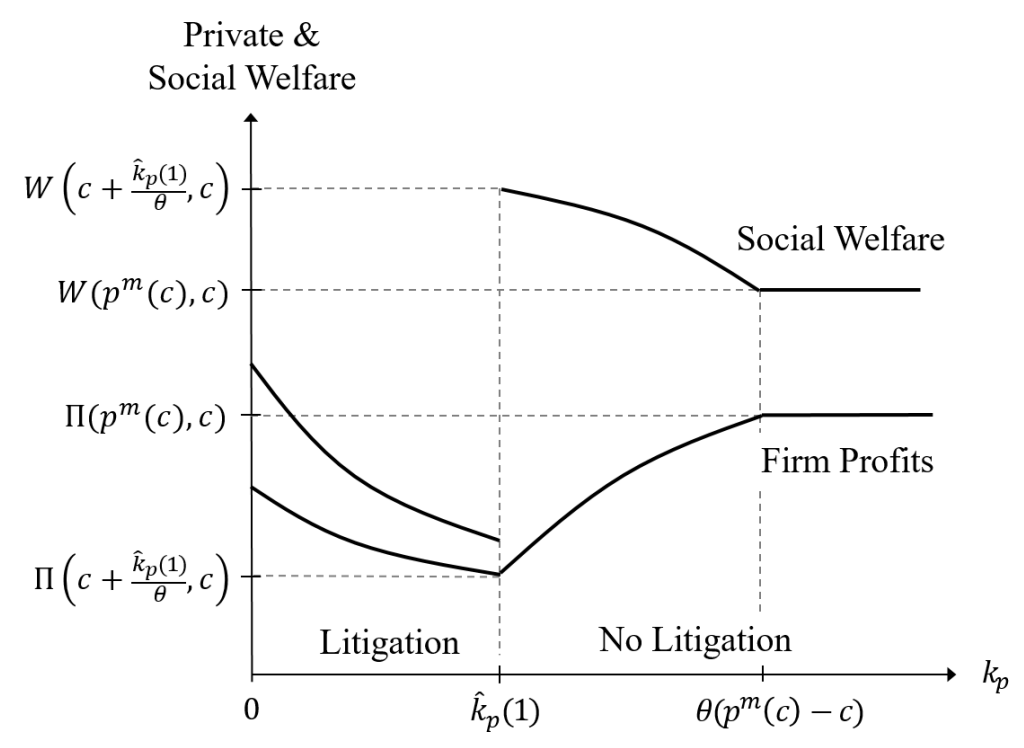

Figure 2: Firm Profits and Social Welfare $(\mu=1)$

$(\mu=1)$, the firms' profits are falling as $k_{p}$ rises in this region, just as they would if the firms' own production costs were to increase. This is a more general result. According to part 1 of Proposition 1, firm profits are decreasing function of $k_{p}$ for all $\mu \in(0,1]$. When consumers are completely myopic $(\mu=0)$, neither the effective price nor firm profits depend on $k_{p}$ (see Figure 3 ). Since consumers do not expect to be recipients of the net damage awards, the firms cannot capture the cost savings either. When $k_{p}<\widehat{k}_{p}(\mu)$, social welfare is a strictly decreasing function of $k_{p}$ for all $\mu \in[0,1]$. Increasing the plaintiff's litigation costs harms social welfare directly - since litigation is even more wasteful - and indirectly through an increase in the effective price and the associated reduction in demand. ${ }^{20}$

Now consider the middle region where $k_{p} \in\left[\widehat{k}_{p}(\mu), \theta\left(p^{m}(c)-c\right)\right)$. The firms lower their prices to $c+k_{p} / \theta$ in order to avoid costly litigation. Consumers do not bring lawsuits after purchasing the product. This helps consumers and also increases social welfare, as shown by the discontinuity of the social welfare function in Figures 2 and 3. The increase in social welfare comes from two sources: (1) more consumers purchase the product because the (effective) price is lower; and (2) there is less wasteful litigation spending. When $k_{p}$ rises within this middle region, firms are better off (since they can raise their prices closer to $p^{m}(c)$ and still avoid lawsuits) but social

\footnotetext{
${ }^{20}$ Note also that even as $k_{p}$ goes to zero, both the social welfare and the firm profits stay below those under the unconstrained monopoly price $\left(p^{m}(c)\right)$. The reason is that even when $k_{p}=0$, firms still face a positive litigation cost $\left(k_{d}>0\right)$, which generates a welfare loss from litigation and also imposes a higher marginal cost on the firms $\left(c+k_{d}\right)$, thereby reducing the aggregate demand.
} 


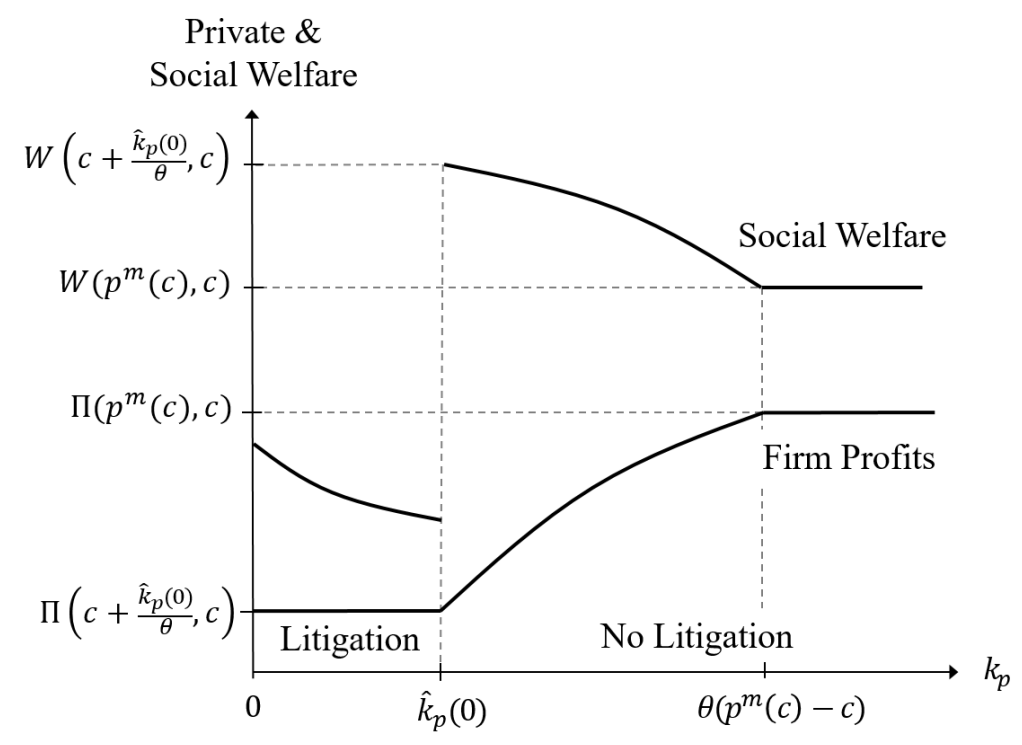

Figure 3: Firm Profits and Social Welfare $(\mu=0)$

welfare falls (as the higher prices harm consumers and create a larger dead-weight loss). Finally, when the consumer-plaintiff's litigation costs are in the highest region, $k_{p}>\theta\left(p^{m}(c)-c\right)$, then the firms charge the unconstrained monopoly price $p^{m}(c)$ and avoid litigation. Increasing $k_{p}$ has no affect on profits or social welfare in this region. The next corollary follows directly from Proposition 1.

Corollary 1. Conditional on $\mu$, firm profits are maximized when plaintiff litigation costs are sufficiently high, $k_{p} \geq \theta\left(p^{m}(c)-c\right)$. Social welfare is maximized when $k_{p}=\widehat{k}_{p}(\mu)>0$.

Corollary 1 tells us that the firms want the plaintiffs' litigation costs to be in the highest range. This makes intuitive sense. Firms would obviously like to squelch all future litigation and charge the unrestricted monopoly price of $p^{m}(c)$. This is possible only when the costs of litigation are prohibitively high, $k_{p} \geq \theta\left(p^{m}(c)-c\right)$ ). More interestingly, Corollary 1 tells us that it is not in society's interest for the plaintiff's litigation costs to be too small. According to Proposition 1 , if $k_{p}=0$, the effective price charged by the firms would be strictly greater than $p^{m}(c)$ and social welfare would be less than $W\left(p^{m}(c), c\right) .{ }^{21}$ If plaintiffs could costlessly bring litigation against the firms for overcharges, the firms would not simply cease their anticompetitive conduct and lower their prices. Instead, they will accept litigation as

\footnotetext{
${ }^{21}$ Even if the firms' litigation cost were zero $\left(k_{d}=0\right)$, firms will still charge $p^{m}(c)$ and earn $\Pi\left(p^{m}(c), c\right)$. As $k_{d} \rightarrow 0$, social welfare will converge to $W\left(p^{m}(c), c\right)$. With costless litigation $\left(k_{p}=\right.$ $\left.k_{d}=0\right)$, we get the invariance result.
} 
another cost of doing business and will raise their prices. Social welfare obtains its maximum value when $k_{p}=\widehat{k}_{p}(\mu)>0$.

\subsubsection{Consumer (Mis)perceptions}

According to Proposition 1 , when $k_{p}<\widehat{k}_{p}(\mu)$, firm profits are strictly increasing in the parameter $\mu$. In other words, firms are better off when consumers are forward looking rather than myopic. Intuitively, holding the price fixed, the firm will sell more of the product when consumers have rational expectations about the damage awards or "rebates" that they will receive through litigation in the future. Comparing Figure 2 with Figure 3 illustrates this result: profits higher in the low range when $\mu=1$ than $\mu=0$. We also see in Figures 2 and 3 that $\widehat{k}_{p}(1)>\widehat{k}_{p}(0)$ : there is more equilibrium litigation when consumers are forward looking than when they are myopic. More generally, raising $\mu$ has the effect of expanding the range of parameter values for which the firms will tolerate litigation in equilibrium (Lemma 2).

Interestingly, changes in the parameter $\mu$ have an ambiguous effect on social welfare. To see why, suppose, first, that $k_{p}=0$. Comparing Figures 2 and Figure 3, we can see social welfare is strictly higher when consumers are fully forward looking. Myopic consumers do not anticipate receiving any litigation surplus and therefore take the market price at face value and purchase less, creating a larger deadweight loss. In contrast, suppose $k_{p} \in\left(\widehat{k}_{p}(0), \widehat{k}_{p}(1)\right)$. Comparing Figures 2 and 3 we see that social welfare is strictly higher when consumers are myopic. When consumers are myopic the firms charge $p=c+k_{p} / \theta$ and deter all litigation. When consumers are forward looking, the firms raise the price and allow litigation, creating a larger deadweight loss and lowering social welfare. The next corollary, which follows directly from Proposition 1, generalizes these findings.

Corollary 2. Let $\widehat{k}_{p}(0)<\widehat{k}_{p}(1)$ be the thresholds defined in Lemma 2 when $\mu=0$ and $\mu=1$, respectively.

1. If $k_{p}<\widehat{k}_{p}(0)$ then firm profits are maximized when $\mu=1$. Social welfare is maximized when $\mu=1(\mu=0)$ if $\frac{k_{p}}{k_{d}}<(>) \frac{\theta}{1-\theta}$.

2. If $k_{p} \in\left[\widehat{k}_{p}(0), \widehat{k}_{p}(1)\right]$ then firm profits are maximized when $\mu=1$ and social welfare is maximized when $\mu=0$.

3. If $k_{p}>\widehat{k}_{p}(1)$ then neither firm profits nor social welfare depend on $\mu$.

As illustrated in Figures 2 and 3, when the litigation costs $k_{p}$ are sufficiently small, both firm profits and social welfare are highest when consumers are forward looking and expect to capture the full litigation surplus $(\mu=1)$. So, when litigation costs are 
sufficiently small, private and social incentives are aligned. When the litigation costs rise, however, the private and social interests diverge. Firm profits are highest when consumers are fully forward looking $(\mu=1)$ and expect to be plaintiffs in litigation; social welfare is highest if consumers are myopic $(\mu=0)$.

\section{Class Actions}

In the United States, individual price-fixing lawsuits are often joined or consolidated into larger claims. Some of these consolidated actions are organized by the plaintiffs themselves. $^{22}$ With voluntary joinders and direct actions, the plaintiffs hire outside lawyers and privately negotiate attorney fee arrangements. ${ }^{23}$ Other consolidated actions are initiated by self-appointed lawyers. In a typical class action with small dispersed plaintiffs, lawyers recruit a small number of "lead plaintiffs" and bring suit on behalf of the absent class members. The class-action attorney has significant control over the litigation and decides how much time and money to spend pursuing the case. At the conclusion of litigation, the attorney is reimbursed for their out-ofpocket expenses (court fees, travel expenses, expert witness fees, etc.) and the court determines the attorney fee.

Rule 23 of the Federal Rules of Civil Procedure requires that the class-action attorney's fee be "reasonable." The courts have considerable discretion in setting attorney fees in class action litigation. The two common approaches that courts use to set attorney fees are the lodestar method and percentage method. With the lodestar method, the court determines a reasonable number of hours to be spent on the case, multiplies that number by a reasonable hourly rate for the lawyer's time, and then makes adjustments for various factors. With a pure percentage method, the court awards the lawyers a percentage of the recovery without considering the number of hours that the lawyers spent on the case. In practice, judges often determine fees using a combination of methods. ${ }^{24}$

We will now adapt the benchmark model from Section 2 to explore the positive and normative implications of class actions in private antitrust litigation. First, class actions allow the consumer-plaintiffs to achieve economies of scale, thus lowering the

\footnotetext{
${ }^{22}$ For example, in the Spring of 2019, supermarket chain Kroger and 32 other retailers settled antitrust claims against StarKist for conspiring with other tuna producers - Chicken of the Sea and Bumble Bee - to fix the price of canned tuna fish. Starkist had settled earlier with Walmart, Target, and Sam's Club. See Armental (2019) and Ritenbaugh (2019).

${ }^{23}$ The plaintiffs' general counsel may also play an active role in the litigation. The private contracts between the plaintiffs and the lawyers do not require approval by the court.

${ }^{24}$ See Eisenberg et al. (2017). In their sample of 458 class-action cases, $54 \%$ of the attorney fees were determined by the percentage method, $38 \%$ by the percentage method combined with a lodestar check, and about $6 \%$ with the pure lodestar method.
} 
per-unit cost of litigation. Second, class actions create a separation of ownership and control of the litigation. This may allow the class-action lawyers to divert the litigation surplus to themselves and possibly to third parties. We will explore the firms' private incentives to block class actions by requiring consumers to sign class action waivers, and the social welfare implications.

\subsection{Economies of Scale}

Economies of scale in class-action litigation are well-documented in the empirical literature. ${ }^{25}$ Eisenberg and Miller (2010), for instance, find that, in percentage terms, the average lawsuit in their sample had an attorney fee-to-recovery ratio of about $25 \%{ }^{26}$ This is significantly lower than the typical contingent fee percentage of $33 \%$ to $40 \%$ in individual litigation. In addition, the attorney fee-to-recovery ratio and the ratio of the other litigation expenses to the recovery (court fees, travel expenses, expert witness fees, etc.) were decreasing in the recovery. For class action lawsuits where the gross recovery was less than $\$ 1.1$ million, the attorney fees were about $38 \%$ of the recovery; for gross recoveries greater than $\$ 175$ million the attorney fees were $12 \%$ of the recovery. ${ }^{27}$

In our benchmark model, consumer-plaintiffs could bring private antitrust lawsuits at a cost of $k_{p}$ (per unit). Now suppose that consumer-plaintiffs can form a class action and obtain economies of scale. When organized as a class, the per-unit litigation cost falls to $k_{p}^{c}<k_{p}{ }^{28}$ Suppose further that the class-action lawyers are compensated for their out-of-pocket expenses and receive "reasonable" compensation for their time and effort. At the conclusion of litigation, the court allows the attorney to collect $k_{p}^{c}{ }^{29}$ (Agency problems, and surplus extraction by class-action lawyers, will be discussed shortly.) Since class actions achieve economies of scale, they clearly serve the interests of the consumer-plaintiffs ex post. The attorney, working on behalf of the consumerplaintiffs, will bring a class-action lawsuit when $\theta(p-c)-k_{p}^{c}>0$. The following proposition describes how the firms' private incentive to block or allow class actions

\footnotetext{
${ }^{25}$ In theory, consolidation could lead to either higher or lower expenditures on litigation. Insofar as the fixed costs of litigation may be shared, the costs as a share of the recovery would fall. On the the other hand, since the stakes are larger, the private incentives of the plaintiffs to spend money to win the case would rise. See Rosenberg and Spier (2014).

${ }^{26}$ Similar results were found by Fitzpatrick (2010).

${ }^{27}$ This pattern is confirmed by Fitzpatrick (2010) and others.

${ }^{28}$ When plaintiffs' multiple lawsuits are consolidated into a single class action, the defendants may also enjoy the economies of scale. We could easily allow the defendant-firms' litigation cost to decrease to $k_{d}^{c}<k_{d}$, but the substantive results will not change.

${ }^{29}$ This is consistent with the lodestar method and the percentage method with a lodestar adjustment. With a pure percentage approach, then percentage $\beta=\frac{k_{p}^{c}}{\theta(p-c)}$ would allow the lawyer to just break even. The lawyer may try to convince the judge to pay more than this, of course.
} 
can either be aligned with or diverge from the social welfare objective.

Proposition 2. Suppose that class actions lower the unit cost of bringing private antitrust lawsuits from $k_{p}$ to $k_{p}^{c}$. Define $\bar{k}_{p}$, such that $\Pi\left(c+\frac{\bar{k}_{p}}{\theta}, c\right)=\left(\frac{1-\theta}{1-\mu \theta}\right) \Pi\left(p^{m}(z), z\right)$ where $z=c+\left(\frac{1-\mu \theta}{1-\theta}\right) k_{d}$. The threshold $\bar{k}_{p}$ exists and satisfies $\bar{k}_{p} \in\left(\widehat{k}_{p}(\mu), \theta\left(p^{m}(c)-c\right)\right)$ when $\mu \in(0,1]$ and $\bar{k}_{p}=\widehat{k}_{p}(\mu)$ when $\mu=0$.

1. If $k_{p}<\widehat{k}_{p}(\mu)$, then firms have a (weak) incentive to allow class actions and, when they do allow class actions, this is socially efficient. Firms' incentive to allow class actions is strict when $\mu \in(0,1]$, and when $\mu=0$, the firms are indifferent.

2. If $k_{p} \in\left[\widehat{k}_{p}(\mu), \bar{k}_{p}\right)$, then there exists a threshold $\underline{k}_{p} \in\left(0, \widehat{k}_{p}(\mu)\right)$ where firms block (allow) class actions if $k_{p}^{c}>\underline{k}_{p}\left(k_{p}^{c} \leq \underline{k}_{p}\right) .{ }^{30}$ When $k_{p}^{c} \leq \widehat{k}_{p}(\mu)$, firms' allowing (blocking) class actions is socially inefficient (efficient). When $k_{p}^{c}>\widehat{k}_{p}(\mu)$, firms' blocking class actions is socially inefficient.

3. If $k_{p} \geq \bar{k}_{p}$, then firms will block class actions. Firms' blocking class actions is weakly socially efficient (inefficient) when $k_{p}^{c}>\widehat{k}_{p}(\mu)\left(k_{p}^{c} \leq \widehat{k}_{p}(\mu)\right)$.

Although the proof is somewhat involved, the reasoning behind the statements Proposition 2 is fairly straightforward. Whether the firms will block or allow class action lawsuits depends on the consumers' individual litigation cost. The easiest case is when $k_{p}<\widehat{k}_{p}(\mu)$. In this case, consumer-plaintiffs will bring individual lawsuits if class actions are blocked. Because litigation takes place in equilibrium and the firms treat that as another cost of doing business, it is in their interest to lower the litigation cost, for instance, by allowing consumers to bring a class action. Interestingly, as the individual litigation cost decreases from $k_{p}$ to $k_{p}^{c}$, not only will the firms' aggregate profits increase, but the social welfare also increases. The increase in social welfare comes from the fact that the deadweight loss from litigation has gotten smaller and also that the lower marginal cost leads to a lower equilibrium price, thereby serving a larger consumer base.

At the opposite end, when $k_{p} \geq \bar{k}_{p}$, because the consumers' litigation cost (without class action) is sufficiently high and firms' profits will only decrease when the consumers' litigation cost decreases, firms have no incentive to allow class actions. Whether the firms' imposing class action waivers is socially efficient depends on the magnitude of $k_{p}^{c}$. If $k_{p}^{c}<\widehat{k}_{p}$, allowing class actions will decrease social welfare (from

\footnotetext{
${ }^{30}$ The threshold $\underline{k}_{p}$ will depend on $k_{p}$. We have suppressed the functional form for the sake of cleaner exposition.
} 
Corollary 1), and the firms' imposing class action waivers is socially efficient. On the

other hand, if $k_{p}^{c} \geq \widehat{k}_{p}(\mu)$, by allowing class actions, while still keeping litigation off the equilibrium path, the equilibrium price will (at least weakly) decrease, thereby increasing social welfare. The firms' imposing class action waivers in that setting is socially inefficient.

Finally, when the consumers' litigation cost (without class action) falls in the middle region, $\widehat{k}_{p}(\mu) \leq k_{p}<\bar{k}_{p}$, whether or not the firms will require a class action waiver depends on both $k_{p}$ and the magnitude of $k_{p}^{c}$. If, for instance, $k_{p}^{c} \geq \widehat{k}_{p}(\mu)$, allowing class actions will only decrease the firms' profits. On the other hand, if $k_{p}^{c}$ is sufficiently close to zero, firms will want to allow class actions in equilibrium. When class actions are allowed, however, social welfare is strictly lower (per Corollary 1). This is because, without the class action, firms are already charging a sufficiently low price to keep litigation off the equilibrium path and, therefore, social welfare is relatively high. When class actions are allowed, social welfare decreases due to all the litigation cost in equilibrium.

\subsection{Surplus Extraction by Lawyers and Third Parties}

There is a general concern that class-action attorneys engage self-dealing behavior and inflate their fees without sufficient oversight by their clients or the courts. ${ }^{31}$ Class actions may be prone to agency problems, since the consumer-plaintiffs formally own the legal claims but the class-action attorneys control the litigation. Consistent with this view, some empirical studies suggest that judges with congested dockets tend to grant higher fees to lawyers (Helland and Klick, 2007). Other scholars point to the fact that the average attorney fee-to-recovery ratio for class-action attorneys of $25 \%$ is smaller than $33 \%$, the standard contingent fee for individual litigation, as evidence that class-action attorneys are not overpaid in the traditional sense. ${ }^{32}$

In addition to class action lawyers, third parties may capture surplus from classaction litigation. For example, the courts often approve so-called "cy pres" distributions of unclaimed funds to charities and non-profit organizations, sometimes handpicked by class-action attorneys. ${ }^{33}$ For example, in a class action lawsuit brought against NASCAR merchandise vendors alleging price fixing, the court approved the class-action lawyer's request to distribute unpaid funds to nine charities including

\footnotetext{
${ }^{31}$ See, for example, Beisner et al. (2005), who state that: "[O]ne of the most heavily criticized class-action abuses has been the use of class-action settlements to generate huge fees for lawyers and little or nothing for the allegedly injured consumers." For more discussion on the debate see Fitzpatrick (2010).

${ }^{32}$ Whether class action attorneys are overpaid on average remains an open empirical question.

${ }^{33}$ See Redish et al. (2010).
} 
the Lawyers Foundation of Georgia and the American Red Cross. ${ }^{34}$ In other circumstances, the court may order that unclaimed class-action recoveries go to the state for use as either general funds or for a particular purpose ("conditional escheat"). ${ }^{35}$ Finally, even in the absence of court-supervised distribution of recovery, non-meritorious plaintiffs' filing and capturing a portion of class recovery can also be thought of as third party capture of surplus.

We now adapt the benchmark model from Section 2 to explore the positive and normative implications of surplus extraction by class-action lawyers and third parties. Suppose that there is a profitable litigation opportunity, $\theta(p-c)-k_{p}>0$, where as before $k_{p}$ includes both the out-of-pocket litigation expenses and the opportunity cost of the lawyer's time. Suppose that net litigation surplus, $\theta(p-c)-k_{p}$, is shared by the consumer-plaintiffs, the class-action attorney, and third parties (e.g. charities and the state). Specifically, assume that fraction $\gamma \in[0,1]$ of the net surplus is captured by the lawyer and the third parties, and the residual $1-\gamma$ goes to the consumer plaintiffs. ${ }^{36}$ Note that the consumer's net return from litigation ex post, $(1-\gamma)\left(\theta(p-c)-k_{p}\right)$, is decreasing in the parameter $\gamma$.

Surplus extraction by class-action lawyers and third parties ex post affects the purchase decisions of consumers ex ante. As in Section 2, the parameter $\mu \in[0,1]$ is the degree to which the consumers are forward looking and anticipate being plaintiffs in litigation. When class-action attorneys and/or third parties capture a share $\gamma$ of the litigation surplus, this dilutes the consumer's expected share from $\mu$ to $\mu(1-\gamma)$. The effective price (as perceived by consumers at the time of purchase) is:

$$
p-\mu(1-\gamma) \max \left\{\theta(p-c)-k_{p}, 0\right\} .
$$

When $\gamma=0$, so the consumer-plaintiffs capture the entire litigation surplus, the effective price is exactly as in equation (4). When $\gamma=1$, the class-action lawyers and third parties capture the litigation surplus so $x(p)=p$. More generally, holding the actual price $p$ fixed, the effective price perceived by consumers is an increasing function of $\gamma$. Surplus extraction by lawyers and third parties is in effect creating an "ad valorem tax" on consumers.

The firms' aggregate profit function is similar to Lemma 1 above. If $\theta(p-c)-k_{p} \leq$

\footnotetext{
${ }^{34}$ See In re Motorsports Merch. Antitrust Litig., 160 F. Supp. 2d 1392, 139599 (N.D. Ga. 2001). Other examples include Fears v. Wilhelmina Model Agency, Inc., No. 02 Civ. 4911 (HB), 2007 U.S. Dist. LEXIS 48151 (S.D.N.Y. July 5, 2007) and In re Baby Prods. Antitrust Litig., 708 F.3d 163 (3d Cir. 2013).

${ }^{35}$ See for example West Virginia v. Chas. Pfizer \& Co. 87440 F.2d 1079 (2d Cir. 1971) and In re Folding Carton Antitrust Litig., 744 F.2d 1252, 1258 (7th Cir. 1984).

${ }^{36}$ Our findings are robust to the particular method of compensation for the lawyer (lodestar, percentage based, etc.). A pure percentage fee $\beta$ that satisfies $\theta \beta(p-c)-k_{p}=\gamma\left[\theta(p-c)-k_{p}\right]$ gives the lawyer a share $\gamma$ of the net surplus. Rearranging terms gives $\beta=(1-\gamma) \frac{k_{p}}{\theta(p-c)}+\gamma$.
} 
0 , lawsuits are not brought and the firms' profits are $\Pi(p, c)$. If $\theta(p-c)-k_{p}>0$, lawsuits are brought and firms' profits are:

$$
\Pi(x(p), c+k)-(1-\mu(1-\gamma)) D(x(p))\left[\theta(p-c)-k_{p}\right]
$$

where $x(p)=p-\mu(1-\gamma)\left[\theta(p-c)-k_{p}\right]$. This is equivalent to equation (6), except that $\mu$ replaced by $\mu(1-\gamma)$. Firm profits are reduced to reflect the value captured by the lawyers and/or third parties. ${ }^{37}$ The firms' pricing strategy and profits are exactly as characterized in Proposition 1, except that the parameter $\mu$ is reduced to $\mu(1-\gamma)$.

The firms clearly have a (weak) incentive to block class-action attorneys and third parties from capturing the net litigation surplus. The lawyers and third parties are imposing a type of "ad valorem tax" on consumers which harms firm profits ex ante. Are the firms' incentives to block class actions aligned with social welfare? To answer this question, we will assume that all the recipients of the litigation surplus - the consumers' future selves, the lawyers, and any third parties (charities and/or the state) - are represented in the social welfare function. ${ }^{38}$ The following proposition describes how the firms' private incentive to block class actions may either be aligned with or diverge from the social welfare objective.

Proposition 3. Suppose that class actions allow lawyers and third parties to capture a share $\gamma \in(0,1]$ of the litigation surplus. ${ }^{39}$ If consumers are completely myopic, $\mu=0$, then firm profits and social welfare are the same with or without class actions. Suppose consumers are not completely myopic, $\mu \in(0,1]$. The threshold defined in Lemma 2 is lower when class actions are allowed, $\widehat{k}_{p}(\mu(1-\gamma))<\widehat{k}_{p}(\mu)$.

1. If $k_{p}<\widehat{k}_{p}(\mu(1-\gamma))$ then firms have a private incentive to block class actions and this is socially efficient (inefficient) if $\frac{k_{p}}{k_{d}}<(>) \frac{\theta}{1-\theta}$.

2. If $k_{p} \in\left[\widehat{k}_{p}(\mu(1-\gamma)), \widehat{k}_{p}(\mu)\right]$ then firms have a private incentive to block class actions and this is socially inefficient.

3. If $k_{p}>\widehat{k}_{p}(\mu)$ then firms and society are indifferent about allowing and blocking class actions.

\footnotetext{
${ }^{37}$ The value captured ex post by the lawyers and third parties is $\gamma D(x(p))\left[\theta(p-c)-k_{p}\right]$, and the unanticipated value captured by consumers is $(1-\mu)(1-\gamma) D(x(p))\left[\theta(p-c)-k_{p}\right]$. Adding these two expressions gives the equation above.

${ }^{38}$ Then, putting aside the costs of litigation and any distortionary effects on the market, the allocation of the litigation surplus $\gamma$ has a neutral effect on social welfare.

${ }^{39}$ Class actions do not change the attorney's opportunity cost of litigation, $k_{p}^{c}=k_{p}$, but may increase the attorney's fee. The surplus captured by attorneys is included in social welfare.
} 
So long as consumers are not completely myopic, $\mu \in(0,1]$, the firms' profits are smaller when lawyers and third parties capture a greater share of the litigation surplus. This is happening because value capture by the lawyers and others reduces the rebate that is received by consumers ex post. This reduces the consumers' demand and lowers the firms' profits. If $\mu=0$, then consumers do not expect to participate in litigation in the future. So, from the firms' perspective, it does not matter if the litigation surplus is captured by the consumers themselves or by the class-action attorneys and/or third parties.

The capture of surplus by lawyers and third parties has ambiguous effects on social welfare. First, as in Section 2, when the costs of litigation are below a threshold then the firms will raise their prices and tolerate litigation in equilibrium. If class-action lawyers and third parties capture litigation surplus, then consumers will purchase less, creating a larger deadweight loss. On the other hand, insofar as surplus extraction reduces the tolerance of the firms for litigation, then the potential for value capture by class-action attorneys and third parties will have a deterrent effect on price fixing. The firms will lower their prices to avoid class actions, and social welfare will rise.

For the sake of tractability, we have examined two issues, the economies of scale and agency problems from allowing class actions, in isolation. Although the analysis is more involved, it is fairly straightforward to see the impact of combining both issues. $^{40}$ In general, as the agency problem becomes more severe (i.e., as $\gamma$ rises), the range of $k_{p}$ where the firms would allow class actions would get smaller. At one extreme, even though the consumers are not completely myopic $(\mu>0)$, when $\gamma$ is above a certain threshold (but less than one), firms will never allow class actions in equilibrium, and this may be socially inefficient. When $\gamma$ is below that threshold, we will be back to the analysis in Proposition 2. As in Proposition 2, firms' incentives of allowing class actions may or may not align with social welfare.

\section{Further Considerations}

Having presented the main analysis, we now consider several extensions. They include: (1) settlement of credible lawsuits, (2) fee shifting between the plaintiffconsumers and the defendant-firms, where the loser pays the fees of the winner (imposition of the "English Rule" or the one-way fee-shifting under the Clayton Act); (3) damages multipliers, such as treble damages; (4) combining private litigation with public enforcement; and (5) sustaining collusive equilibrium through repeat play. The formal analyses and proofs for these extensions may be found in Appendix B.

\footnotetext{
${ }^{40}$ The complexity stems from the fact that, now we will have two separate sets of profit and social welfare curves (with two separate $\widehat{k}_{p}$ 's). A more complete analysis is available from the authors.
} 


\subsection{Settlement}

In the main model, cases go to trial whenever the firms charge $p>c+k_{p} / \theta$. Since trials are costly, the firms and the consumers have a joint incentive to settle out of court to avoid the costs of litigation $\left(k=k_{p}+k_{d}\right)$. When our framework is extended to include out-of-court settlement, new insights emerge. If consumers fully anticipate the future settlement rebate $(\mu=1)$, the firms can realize the unconstrained monopoly profit, with or without class action waivers. When consumers do not fully anticipate the settlement rebate $(\mu<1)$ then the firms' profits lower and firms may (depending on $k_{p}^{c}$ ) have an incentive to impose class action waivers.

Suppose that information is symmetric at the time of settlement bargaining: all the relevant parameters (including whether the consumers made a purchase) are common knowledge. We model settlement negotiations using simple Nash bargaining where $\alpha \in[0,1]$ represents the defendants' (firms') bargaining power. ${ }^{41}$

If $p \leq c+k_{p} / \theta$, the plaintiffs do not have a credible threat to go to trial, so no lawsuits are brought and the aggregate firm profits are $\Pi(p, c)$. If $p>c+k_{p} / \theta$, the plaintiffs have a credible threat to go to trial. The least the plaintiffs would be willing to accept to settle the case is $\underline{s}(p)=\theta(p-c)-k_{p}$, and the most the defendants would be willing to pay is $\bar{s}(p)=\theta(p-c)+k_{d}$. The case therefore settles for $s(p)=\alpha \underline{s}(p)+(1-\alpha) \bar{s}(p)$, or:

$$
s(p)=\theta(p-c)+k_{d}-\alpha\left(k_{p}+k_{d}\right) .
$$

Note that the firms capture fraction $\alpha$ of the bargaining surplus, $k=k_{p}+k_{d}$. Since the case will settle for $s(p)$, the effective price perceived by the consumers is

$$
x(p)=p-\mu s(p) .
$$

If $\mu=1$, the consumers are fully forward-looking and anticipate the "settlement rebate" of $s(p)$ at the time of purchase. If $\mu<1$, the settlement rebate is less-thanfully anticipated. Using (11) and (12), aggregate firm profits when $p>c+k_{p} / \theta$ are

$$
\Pi(x(p), c)-(1-\mu) D(x(p)) s(p) .
$$

It is interesting to compare the profit function in (13) to the profit function in (6) when settlement is impossible. In $(13)$, the first term $\Pi(x(p), c)$ represents the profits of a monopolist with the effective price of $x(p)$ and the production cost of $c$. By contrast, in (6), the first term $\Pi(x(p), c+k)$ includes the cost of litigation $k$. This

\footnotetext{
${ }^{41}$ This is equivalent to a random-offeror model where $\alpha$ is the probability that the defendant makes the offer. One could also use an alternating offer bargaining protocol; different discount factors for the consumers and firms would yield an uneven division of surplus.
} 
difference makes sense, since the parties avoid the litigation costs by setting out of court. The second term in (13) is the value captured by myopic consumers. When $\mu<1$, the settlement $s(p)$ is less-than-fully anticipated by consumers at the time of purchase, and this has a negative effect on the firms' aggregate profits.

Equation (13) implies that when consumers are fully forward-looking, $\mu=1$, the firms obtain the unconstrained monopoly profit regardless of the litigation costs $\left(k_{p}\right.$ and $k_{d}$ ) and the bargaining power $\alpha$. With frictionless Nash bargaining, the firms can simply raise the actual price of the product to the point where the effective price $x(p)=p^{m}(c)$. Since consumers fully anticipate the settlement rebate $s(p)$, the firms obtain the unconstrained monopoly profit $\Pi\left(p^{m}(c), c\right)$. When consumers are at least party myopic, $\mu<1$, then the profits in (13) are lower than $\Pi\left(p^{m}(c), c\right)$.

Appendix B shows that when the plaintiffs' cost of litigation is below a threshold value, the firms will accept lawsuits (and subsequent settlement) as a cost of doing business. Interestingly, in contrast to our earlier results, firm profits and social welfare increase when the plaintiffs' litigation cost $k_{p}$ rises. This happens because the settlement value in (11) falls when $k_{p}$ rises, and so the unanticipated transfer of value from the firm to the myopic consumers is smaller. So, the firms and society are better off when class actions are blocked. When the plaintiffs' cost $k_{p}$ rises above the threshold value, the firms will lower the actual price and push litigation and settlement off the equilibrium path. The firms have a socially excessive incentive to impose class action waivers on consumers in this case.

\subsection{Fee Shifting}

In the main analysis, the plaintiff and the defendant were responsible for paying their own litigation costs regardless of the outcome at trial. This is the rule typically used in the United States (the "American Rule"). Suppose instead that the loser in litigation must reimburse the winner for the litigation costs (the "English Rule"). If we let $\theta \in$ $(0,1)$ represent the plaintiff's probability of winning at trial then, with fee-shifting, the plaintiff's and defendant's expected litigation costs become $k_{p}^{e r}=(1-\theta)\left(k_{p}+k_{d}\right)$ and $k_{d}^{e r}=\theta\left(k_{p}+k_{d}\right)$, respectively.

A change from the American Rule to the English Rule may increase or decrease prices, profits, and social welfare depending on whether $\theta$ is smaller than or greater than $\frac{k_{d}}{k_{p}+k_{d}}$. If $\theta>\frac{k_{d}}{k_{p}+k_{d}}$, the plaintiff is likely to win at trial and the plaintiff's expected litigation costs are lower under the English Rule than the American Rule. If $\theta<\frac{k_{d}}{k_{p}+k_{d}}$, the plaintiff is likely to lose at trial and the plaintiff's expected litigation costs are higher under the English Rule. All of the results of the benchmark model will continue to hold, with the threshold $\widehat{k}_{p}^{e r}(\mu)$, determined by equation (8), but 
using $k_{p}^{e r}$ and $k_{d}^{e r}$, instead of $k_{p}$ and $k_{d}$, respectively. ${ }^{42}$

Before we proceed, one unique aspect about private antitrust lawsuits in the U.S. is that it utilizes one-way fee-shifting for the benefit of the plaintiffs. Under Clayton Act $\S 4(\mathrm{a})$, when the plaintiffs prevail, they are entitled to recover "the cost of suit, including a reasonable attorneys fee" from the defendants. The defendants, on the other hand, do not recover their expenses from the plaintiffs when they prevail and are subject to the American rule. With plaintiff-friendly, one-way fee-shifting, the plaintiff's and defendant's expected litigation costs become $k_{p}^{c a}=(1-\theta) k_{p}$ and $k_{d}^{c a}=$ $k_{d}+\theta k_{p}$, respectively. The threshold $\widehat{k}_{p}^{c a}(\mu)$ is determined by equation (8), and will of course be the same as the value $\widehat{k}_{p}(\mu)$ in Proposition 1 . Since $k_{p}^{c a}=(1-\theta) k_{p}<k_{p}$, the threshold value for the plaintiff's litigation cost will be higher. With lower plaintiff litigation cost, keeping litigation off the equilibrium path becomes less attractive for the firms and they become more likely to allow litigation in equilibrium.

\subsection{Damage Multipliers}

In private antitrust suits, plaintiffs are sometimes entitled to recover multiple times the actual harm suffered (e.g., treble damages under Clayton Act $\S 4(\mathrm{a})$ ). While multiple damages provide a stronger ex post incentive to the consumers to bring suit, previous literature has cast doubt on whether it works as deterrence (Easterbrook 1985; Salant 1987; Baker 1988). The basic story, similar to ours with fully forwardlooking consumers $(\mu=1)$, is that, with higher damages, consumers would become willing to pay more for the product and the firms can charge a higher price ex ante, so that, in the end, firms realize the same expected monopoly profit and the consumers obtain the same expected surplus. What is important in the analysis, however, are the assumptions that (1) the ex post private litigation is costless and (2) there is less than full deterrence $(\theta<1)$. ${ }^{43}$

In the main model, $\theta$ was the expected fraction of the overcharge $(p-c)$ awarded to the plaintiffs in litigation. We can reflect a damages multiplier by adjusting $\theta$. For example, if there is a $25 \%$ chance of winning the cases, and only compensatory damages are awarded ( $100 \%$ of the overcharge), then $\theta=.25 \times 1=.25$. If, on the other hand, treble damages are awarded (300\% of the overcharge), then $\theta=.25 \times 3=.75$. The bigger the damages multiplier, the higher the $\theta$. With a sufficiently generous damages multiplier, we may even have $\theta \geq 1$.

\footnotetext{
${ }^{42}$ In Appendix B, we show that $\widehat{k}_{p}^{e r}(\mu)$ may be larger than or smaller than $\widehat{k}_{p}(\mu)$, depending on the parameter $\theta$.

${ }^{43}$ This is similar to our extension in Section 4.1 where all cases settle and the parties do not incur any litigation cost in equilibrium. There, when consumers are fully forward-looking $(\mu=1)$, the firms achieve monopoly profits $\Pi\left(p^{m}(c), c\right)$ for all $\theta<1$.
} 
Recall that Proposition 1 characterizes the equilibrium price, litigation decisions, firm profits, and social welfare when $\theta<1$. If consumers are fully forward-looking,

$\mu=1$, and $k_{p}<\widehat{k}_{p}(\mu)$, the neutrality result holds: as $\theta$ rises, firms increase the price to offset the more generous rebate and earn the same aggregate profit. However, when $\theta$ rises the threshold $\widehat{k}_{p}(\mu)$ rises as well. Intuitively, as $\theta$ rises, pushing litigation off the equilibrium path becomes less attractive because the profit margin $\left(k_{p} / \theta\right)$ decreases, so there is more litigation in equilibrium. This also implies that, with respect to class action waivers, in a broader parameter space (or $k_{p}$ space), firms will have an incentive to reduce the consumers' litigation cost $\left(k_{p}\right)$ which will also increase welfare.

If $\theta<1$ and consumers are not fully forward-looking $(\mu<1)$, however, the neutrality result no longer holds: equilibrium prices, litigation decisions, profits and welfare depend on the parameter $\theta$. In case 1 of Proposition 1 , as $\theta$ rises, because the myopic consumers' purchase decision is unaffected by the change in $\theta$ but the firms' expected litigation payment $\left(\theta(p-c)+k_{d}\right)$ rises, and their aggregate profit falls. At the same time, pushing litigation off the equilibrium path also becomes unattractive, for the same reason as with the fully forward-looking consumers. This makes the effect of a change in $\theta$ on $\widehat{k}_{p}$ ambiguous. For instance, when $\theta$ is relatively small, a small increase can have a big effect on the profits the firms can earn by pushing litigation off the equilibrium path but a relatively small effect on the profits in case they allow litigation. The effects can be reversed when $\theta$ is relatively large. The effects on the firms' incentive to impose class action waivers are similarly ambiguous.

Finally, if $\theta \geq 1$, then one can show that $\widehat{k}_{p}(\mu)=0$; it is no longer in the firms' interest to allow litigation in equilibrium regardless of $\mu$. If the firms set a price $p>c+k_{p} / \theta$ then lawsuits are brought and the firms realize a negative profit. However, firms can still set $p=c+k_{p} / \theta$, push litigation off the equilibrium path and earn positive profits (with the profit margin of $k_{p} / \theta$ ). Given that the size of consumers' litigation cost directly translates to the size of profit margins, firms will have a strong incentive to increase $k_{p}$ as much as they can. With $\theta \geq 1$, therefore, firms will surely impose class action waivers on consumers and block class actions. This is socially inefficient since it allows the firms to charge a higher price and this generates a larger deadweight loss.

\subsection{Public Enforcement}

As discussed earlier, most antitrust lawsuits in the US are pursued by private parties independently of any government action. ${ }^{44}$ At the same time, there are also many

\footnotetext{
${ }^{44}$ See Crane (2011), Lande and Davis (2007), and Kauper and Snyder (1986). In 2018, for instance, there were 318 antitrust class action complaints filed and $\$ 5.3$ billion in private antitrust settlements. See Davis and Kohles (2019). In contrast, the U.S. Department of Justice filed 18 criminal antitrust cases in 2018 and obtained $\$ 172$ million in criminal fines and penalties. See
} 
examples of private antitrust lawsuits that follow on the enforcement actions by the DOJ or the FTC. ${ }^{45}$ In this section, we examine the possibility of private antitrust lawsuits piggy-backing on public enforcement efforts. ${ }^{46}$ Our analysis, while simple and stylized, shows that our main insights hold, albeit with some new and interesting variations.

Suppose that a public enforcement agency is tasked with detecting and penalizing price-fixing violations. When the firms collude and set a market price $p>c$, they are detected with probability $\sigma \in(0,1)$ and pay a monetary fine of $\tau D(x(p))(p-c)+F$, where $\tau \in[0,1]$ stands for pro rata penalty and $F \geq 0$ stands for fixed penalty. ${ }^{47}$ Without any private antitrust lawsuits, when firms collude at $p>c$, they expect to realize expected aggregate profits of $(1-\sigma \tau) D(p)(p-c)-\sigma F$. Note that if the firms decide to collude, they will charge the monopoly price $p^{m}(c)$. The threat of public enforcement will deter collusion if the fine is sufficiently high: $\sigma F>(1-\sigma \tau) \Pi\left(p^{m}(c), c\right)$. When $\sigma F<(1-\sigma \tau) \Pi\left(p^{m}(c), c\right)$, on the other hand, public enforcement by itself will not deter collusion. In this case, the threat of follow-on private antitrust lawsuits may serve a valuable complementary role to public enforcement.

Regarding private enforcement, suppose that private plaintiffs enjoy spillovers from public enforcement. If collusion is detected by the public enforcement agency, consumers and their attorneys have the option to bring private antitrust lawsuits. ${ }^{48}$ As in the main analysis, when $p \leq c+k_{p} / \theta$, consumers do not bring suit and the firms realize an aggregate profit of $D(p)(1-\sigma \tau)(p-c)-\sigma F$. If $p>c+k_{p} / \theta$, on the other hand, after collusion is detected by the public enforcement authority (with probability $\sigma$ ), consumers exercise the option to bring a follow-on private antitrust lawsuit. At the time of purchase, the effective price perceived by the consumers

https://www.justice.gov/atr/criminal-enforcement-fine-and-jail-charts.

${ }^{45}$ Interestingly, there are also cases where the government piggybacks on the private antitrust actions. See for example United States v. United States Gypsum Co., 438 U.S. 422 (1978), Kauper and Snyder (1986, 1169), and Lande and Davis (2008, 897 and Table 3).

${ }^{46}$ See the interesting recent work of Katsoulacos et al. (2020), and the literature review therein. Future work might also explore leniency programs and rewards for whistleblowers. For recent surveys and discussion see Marx et al. (2015) and Spagnolo and Marvão (2016).

${ }^{47}$ For simplicity, we assume that the fine depends on the actual quantity purchased by consumers and that $\tau$ and $\sigma$ are invariant with respect to $p$. For more general representations see Bos et al. (2018) and Katsoulacos et al. (2020). If we have a more progressive penalty rate, public enforcement will have a stronger deterrence effect. These considerations are beyond the scope of the current paper. We also assume, for simplicity, that public enforcement does not incur any dispute resolution costs like the private actions.

${ }^{48}$ For simplicity, we assume that if the public enforcement agency does not detect wrongdoing then private antitrust lawsuits are too weak to pursue independently but allowing for more general interdependence will not change the main result. 
includes the expected rebate from future litigation:

$$
x(p)=p-\sigma \mu\left(\theta(p-c)-k_{p}\right) .
$$

Note that a higher detection probability $\sigma$ benefits the private plaintiffs ex post. Taking into account the firms' litigation costs $k_{d}$, the private damage payments, and public penalties, aggregate firm profits, when $p>c+k_{p} / \theta$, may be written as:

$$
D(x(p))\left[(1-\sigma(\tau+\theta))(p-c)-\sigma k_{d}\right]-\sigma F .
$$

From the expression, when $\sigma(\tau+\theta) \geq 1$, the firms' profits are strictly negative for all $p>c+k_{p} / \theta$. As for the case of damage multipliers, the compound effect of public and private sanctions can create a very strong incentive for the firms to lower their prices to avoid private antitrust litigation.

Appendix B shows that our core insights extend to settings where private antitrust lawsuits piggyback on government actions. When public enforcement efforts are insufficient to by themselves deter cartel activity, private enforcement actions can either increase or decrease social welfare. As in the main model, if the consumer-plaintiffs' cost of litigation $k_{p}$ are in a middle region, the threat of private antitrust actions will constrain the cartel's prices and increase social welfare. When $k_{p}$ is in a low region, the firms will treat the future litigation costs and private antitrust damages as a cost of doing business and social welfare falls. Interestingly, in the low region, the analysis shows that a higher pro rata penalty rate $(\tau)$ will lead the firms to increase the equilibrium price and further reduce social welfare. The reason is that, unlike the damage payments in private actions, a larger pro rata penalty $\tau$ does not function as a "rebate" to the consumers. Rather, a larger pro rata penalty increases the effective marginal cost for the firms without any corresponding increase in demand.

\subsection{Sustaining Collusion through Repeat Play}

The final variation we examine is how firms can sustain collusion through repeat play. Our main analysis assumed that the cartel members act as a single entity when setting price, and therefore implicitly assumed that the firms have an enforcement technology to support the joint profit-maximizing pricing scheme in Proposition 1. This variation explores the repeated pricing game where the firms choose prices at discrete intervals. We will assume that the cartel members have a common discount rate between rounds, $r>0$, have unlimited capacity to serve the market, and that deviations are easily detected. If a cartel member deviates, then the firms use grimtrigger punishment strategies where the firms charge $p=c$ forever (Nash reversion). ${ }^{49}$

\footnotetext{
${ }^{49}$ Grim-trigger strategies create the most favorable condition for collusion.
} 
One can easily construct the conditions for sustaining the collusive equilibrium when a firm who deviates from the collusive agreement is exempt from antitrust liability. ${ }^{50}$ Recall in Proposition 1 , when $k_{p} \geq \widehat{k}_{p}(\mu)$, the firms charge $p=\min \{c+$ $\left.k_{p} / \theta, p^{m}(c)\right\}$ and deter lawsuits. If they can sustain this outcome, each firm could earn per-period profits of $\Pi(p, c) / N .^{51}$ The most profitable unilateral deviation is to undercut the market by a small amount, $\varepsilon>0$, and capture the entire market. The deviating firm would gain $\Pi(p-\varepsilon, c)-\Pi(p, c) / N$ in that round but would lose $\Pi(p, c) / N$ in all future rounds. This deviation is profitable when the short run-gain exceeds the long run loss: $\Pi(p-\varepsilon, c)-\Pi(p, c) / N>\frac{1}{r N} \Pi(p, c)$. Taking $\varepsilon$ to zero, the outcome in Proposition 1 can be sustained through repeat play when the discount rate is below a threshold, $r \leq \frac{1}{N-1}$.

Now suppose, instead, that $k_{p}<\widehat{k}_{p}(\mu)$. According to Proposition 1, the firms would charge an effective price of $p^{m}(c+\widetilde{k})>p^{m}(c)$ and accommodate litigation in equilibrium. If they can sustain this outcome, the firms could earn profits of $\Pi\left(p^{m}(c+\widetilde{k}), c+\widetilde{k}\right) / N$ each. Undercutting the cartel's price slightly is no longer the most profitable deviation. Since (by assumption) the deviating firm avoids litigation and its associated costs - and the consumers do not expect to receive any litigation rebate if they purchase from the deviating firm - the most profitable deviation is to charge $p^{m}(c)$. Notice that since the deviating firm will not be sued, its short-run profits, $\Pi\left(p^{m}(c), c\right)$, exceed $\Pi\left(p^{m}(c+\widetilde{k}), c+\widetilde{k}\right)$. The incentive to cheat is relatively strong, and so the requisite threshold for the discount rate is strictly smaller than $\frac{1}{N-1}$.

\section{Concluding Remarks}

The paper has examined the effect of class actions and class action waivers in the context of private antitrust lawsuits, in particular, lawsuits against collusion among competitors. Class action waivers, often through mandatory individual arbitration clauses, have received much attention especially since the U.S. Supreme Court has endorsed such private ordering mechanism. The paper has shown that whether the firms will require the consumers to waive their right to bring a class action depends on the consumers' individual litigation cost. Furthermore, depending on the circumstances, firms' incentive in seeking class action waivers can be aligned with the social

\footnotetext{
${ }^{50}$ Appendix $\mathrm{B}$ also considers the case where the deviating firm is liable for overcharges. It is not entirely clear whether a deviating firm should be subject to antitrust liability. On the one hand, a deviating firm is technically not "colluding" with the other firms, but, on the other, when the deviating firm slightly undercuts the collusive price, it may deemed to be "coordinating" with other firms. See also Bos et al. (2018).

${ }^{51}$ Equal division of the market creates the most favorable condition for collusion.
} 
objective. This is the case, for instance, when the consumers' litigation costs are relatively low so that the firms treat litigation in equilibrium as just another cost of doing business. The paper has also shown that the core results remain robust to out-of-court settlement, fee shifting, damage multipliers, combining private antitrust litigation with public enforcement, and sustaining collusion through repeat play.

While the current focus of the paper was on price fixing and private antitrust lawsuits, the analysis is applicable to other settings where the firms' pre-sale behavior can affect the terms of trade. Examples include product design (product liability and consumer financial contracts), false advertising (Concepcion), employment (Epic Systems), and unlawful monopolization (Italian Colors). In the products liability setting, for instance, firms may fundamentally lack sufficient ex ante incentives to design safer products. ${ }^{52}$ The class action can be an effective mechanism for aligning the firm's private incentives with those of society. If firms can block consumers from using the class action mechanism, forcing them to pursue individual actions, then product safety is clearly compromised. Firms also have a strong incentive to minimize or eliminate product liability lawsuits ex post. ${ }^{53}$ We plan to broaden our analysis to other settings where pre- and post-sale behavior of the firm could play an important role in choosing the litigation regime (e.g., asking for a class action waiver).

\footnotetext{
${ }^{52}$ In Choi and Spier (2014), competitive firms reduce safety levels in order to cream-skim the low risk consumers. In Hua and Spier (2020), firms tailor the product to suit the needs of the marginal consumer instead of the average consumer. Safety is suboptimal if the marginal consumer has a lower willingness to pay for safety than the average consumer. In Hamada (1975), consumers systematically underestimate product risks. In these and other settings, products liability induces firms to design safer products.

${ }^{53}$ The ex post incentive to minimize or eliminate product liability lawsuits for the firm that has produced a (likely) defective product is clear. Even for the firm that has produced a (likely) nondefective product, to the extent that there could be frivolous litigation, the firm would want to minimize or eliminate product liability lawsuit ex post.
} 


\section{References}

[1] Ackerman, Andrew and Yuka Hayashi. "Congress Makes It Harder to Sue the Financial Industry." The Wall Street Journal, October 24, 2017.

[2] Aggarwal, Dhruv, Albert H. Choi, and Ofer Eldar. "Federal Forum Provisions and the Internal Affairs Doctrine." Harvard Business Law Review, Vol. 10 (2020), pp. 383-434.

[3] Armental, Maria. "StarKist, Kroger Settle over Tuna Price." Wall Street Journal, 18 March 2019.

[4] Baker, Jonathan. "Private Information and the Deterrent Effect of Antitrust Damage Remedies." Journal of Law, Economics and Organization, Vol. 4 (1988), pp. 385-408.

[5] Beisner, John H., Matthew Shors, and Jessica Davidson Miller. "Class Action 'Cops': Public Servants or Private Entrepreneurs?" Stanford Law Review, Vol. 57 (2005), pp. 1441-1474.

[6] Besanko, David and Daniel Spulber. "Are Treble Damages Neutral? Sequential Equilibrium and Private Antitrust Enforcement." American Economic Review, Vol. 80 (1990), pp. 870-887.

[7] Bone, Robert G. "Class Action."In Chris William Sanchirico (ed.), Procedural Law and Economics, (2012). Cheltenham: Edward Elgar Publishing Co.

[8] Bos, Iwan, Stephen Davies, Joseph E. Harrington Jr., and Peter L. Ormosi. "Does Enforcement Deter Cartels? A Tale of Two Tails." International Journal of Industrial Organization, Vol. 59 (2018), pp. 372-405.

[9] Breit, William and Kenneth G. Elzinga. "Antitrust Enforcement and Economic Efficiency: The Uneasy Case for Treble Damages." Journal of Law and Economics, Vol. 17 (1974), pp. 329-56.

[10] Bureau of Consumer Financial Protection. "Arbitration Agreements." Federal Register, Vol. 82 (2017), pp. 33210-33434.

[11] Che, Y-K. "Equilibrium Formation of Class Action Suits." Journal of Public Economics, Vol. 62 (1996), pp. 339-361.

[12] Che, Y-K. and Kathryn Spier. "Exploiting Plaintiffs through Settlement: Divide and Conquer." Journal of Institutional and Theoretical Economics, Vol. 164 (2008), pp. 4-23. 
[13] Choi, Albert H. and Kathryn Spier. "Should Consumers be Permitted to Waive Products Liability? Product Safety, Private Contracts, and Adverse Selection." Journal of Law, Economics, and Organization, Vol. 30 (2014), pp. 734-766.

[14] Choi, Albert H. and Kathryn Spier. "The Economics of Class Action Waivers." forthcoming in Yale Journal on Regulation (2021).

[15] Crane, Daniel A. The Institutional Structure of Antitrust Enforcement. Oxford University Press (2011).

[16] Dam, Kenneth W. "Class Actions: Efficiency, Compensation, Deterrence and Conflict of Interest." Journal of Legal Studies, Vol. 4 (1975), pp. 47-73.

[17] Davis, Joshua P. and Rose Kohles. "2018 Antitrust Annual Report: Class Action Filings in Federal Court." University of San Francisco Law Working Paper, May (2019). Available at SSRN: https://ssrn.com/abstract=3386424.

[18] Drahozal, Christopher. "Unfair' Arbitration Clauses." University of Illinois Law Review, Vol. 2001 (2001), pp. 695-790.

[19] Easterbrook, Frank H., "Detrebling Antitrust Damages." Journal of Law and Economics, Vol. 28 (1985), pp. 445-67.

[20] Eisenberg, Theodore and Geoffrey Miller. "Attorneys' Fees and Expenses in Class Action Settlements: 1993-2008. "Journal of Empirical Legal Studies, Vol. 7 (2010), pp. 248-281.

[21] Eisenberg, Theodore, Geoffrey Miller, and Roy Germano. "Attorney's Fees in Class Actions: 2009-2013." New York University Law Review, Vol. 92 (2017), pp. 937-970.

[22] Eisenberg, Theodore, Geoffrey Miller, and Emily Sherwin. "Arbitration's Summer Soldiers: An Empirical Study of Arbitration Clauses in Consumer and Nonconsumer Contracts." University of Michigan Journal of Law Reform, Vol. 41 (2008), pp. 871-96.

[23] Elhauge, Einer, "How Italian Colors Guts Private Antitrust Enforcement by Replacing It with Ineffective Forms of Arbitration." Fordham International Law Journal, Vol. 38 (2015), pp. 771-77.

[24] Fitzpatrick, Brian. "An Empirical Study of Class Action Settlements and Their Fee Awards." Journal of Empirical Legal Studies, Vol. 7 (2010), pp. 811-846. 
[25] Fitzpatrick, Brian. "Do Class Action Lawyers Make Too Little?" University of Pennsylvania Law Review, Vol. 158 (2010), pp. 2043-2083.

[26] Gilles, Myriam. "Opting Out of Liability: The Forthcoming, Near-Total Demise of the Modern Class Action." Michigan Law Review, Vol. 104 (2005), pp. 373430 .

[27] Helland, Eric and Jonathan Klick. "The Effect of Judicial Expedience on Attorney Fees in Class Actions. " Journal of Legal Studies, Vol. 36 (2007), pp. $171-187$.

[28] Hua, Xinyu and Kathryn Spier. "Product Safety, Contracts, and Liability." RAND Journal of Economics, Vol. 51 (2020), pp. 233-259.

[29] Hylton, Keith. "The Economics of Class Actions and Class Action Waivers." Supreme Court Economic Review, Vol. 23 (2015), pp. 305-339.

[30] Katsoulacos, Yannis, Evgenia Motchenkova, and David Ulph. "Combining Cartel Penalties and Private Damage Actions: The Impact on Cartel Prices." forthcoming in International Journal of Industrial Organization (2020).

[31] Kauper, Thomas E. and Edward A. Snyder, "An Inquiry into the Efficiency of Private Antitrust Enforcement: Follow-on and Independently Initiated Cases Compared." The Georgetown Law Journal, Vol. 74 (1985), pp. 1163-1230.

[32] Lande, Robert H. and Joshua P. Davis, "Benefits From Private Antitrust Enforcement: An Analysis of Forty Cases." University of San Francisco Law Review, Vol. 42 (2007), pp. 879-918.

[33] Marx, Leslie M., Claudio Mezzetti, and Robert C. Marshall. "Antitrust Leniency with Multiproduct Colluders." American Economic Journal: Microeconomics, Vol. 7 (2015), pp. 205-40.

[34] Miller, Geoffrey. "Class Actions." In Peter Newman (ed.), The New Palgrave Dictionary of Economics and the Law, vol. 1. London: Macmillan Reference Limited (1998), pp. 257-262

[35] Redish, Martin H., Peter Julian and Samantha Zyontz. "Cy Pres Relief and the Pathologies of the Modern Class Action: A Normative and Empirical Analysis." Florida Law Review, Vol. 62 (2010), pp. 617-656.

[36] Resnik, Judith. "Diffusing Disputes: The Public in the Private of Arbitration, the Private in Courts, and the Erasure of Rights." Yale Law Journal, Vol. 124 (2015), pp. 2804-2939. 
[37] Ritenbaugh, Stephanie. "Price-Fixing Cases Against Tuna Firms are Now a Class Action." Pittsburgh Post-Gazette, 8 August 2019.

[38] Rosenberg, David and Kathryn Spier. "Incentives to Invest in Litigation and the Superiority of the Class Action." Journal of Legal Analysis, Vol. 6 (2014), pp. 305-365.

[39] Salant, Steven W., "Treble Damage Awards in Private Lawsuits for Price Fixing." Journal of Political Economy, Vol. 95 (1987), pp. 1326-36.

[40] Schwartz, David, "Mandatory Arbitration and Fairness. " Notre Dame Law Review, Vol. 84 (2009), pp. 1247-1341.

[41] Spagnolo, Giancarlo and Catarina Marvão. "Cartels and Leniency: Taking Stock of What We Learnt." In Luis C. Corchón and Marco A. Marini, eds., Handbook of Game Theory and Industrial Organization. Massachusetts: Edward Elgar Publishing, (2016)

[42] Spulber, Daniel. Regulation and Markets. MIT Press (1989).

[43] Ware, Stephen. "Paying the Price of Process: Judicial Regulation of Consumer Arbitration Agreements." Journal of Dispute Resolution, Vol. 2001 (2001), pp. 89-100. 


\section{Appendix A}

Proof of Lemma 1. The case where $p \leq c+k_{p} / \theta$ was proven in the text. Suppose $p>c+k_{p} / \theta$. We now show that (5) and (6) are equivalent. Rewrite the second part of the profit function from (6) as:

$$
D(x(p))\left(x(p)-c-k_{p}-k_{d}\right)-(1-\mu) D(x(p))\left[\theta(p-c)-k_{p}\right] .
$$

Substituting for $x(p)$ from (4), this becomes

$$
\begin{gathered}
D(x(p))\left[p-\mu\left(\theta(p-c)-k_{p}\right)-c-k_{p}-k_{d}\right]-(1-\mu) D(x(p))\left[\theta(p-c)-k_{p}\right] \\
=D(x(p))\left[p-c-k_{p}-k_{d}\right]-\mu D(x(p))\left[\theta(p-c)-k_{p}\right]-(1-\mu) D(x(p))\left[\theta(p-c)-k_{p}\right] \\
=D(x(p))\left[p-c-k_{p}-k_{d}\right]-D(x(p))\left[\theta(p-c)-k_{p}\right] \\
=D(x(p))\left[p-c-\left(\theta(p-c)+k_{d}\right)\right] .
\end{gathered}
$$

These are the firm's aggregate profits in (5). Piecewise continuity is immediate. Now consider the comparative statics for $\mu$. From (4) we see that $x(p)$ is weakly decreasing in $\mu$. Therefore $D(x(p))$ is weakly increasing in $\mu$, so the firm profits in (5) are weakly increasing in $\mu$.

Proof of Lemma 2. Consider first the left-hand side of (8). When $k_{p}=0$, the lefthand side of $(8)$ is $\Pi(c, c)=0$. When $k_{p}=\theta\left(p^{m}(c)-c\right)$ the left-hand side is $\Pi\left(p^{m}(c), c\right)$, the monopoly profit without the threat of litigation. The left-hand side of $(8)$ is strictly increasing in $k_{p}$ in the range $\left(0, \theta\left(p^{m}(c)-c\right)\right) .{ }^{54}$

We will now show that the right-hand side of (8) is positive, decreasing in $k_{p}$, and smaller than $\Pi\left(p^{m}(c), c\right)$. To facilitate this, we will rewrite the profit function. Using (5), we can rewrite the right-hand side of (8) as

$$
\max _{x}\left\{D(x)\left[p(x)-c-\left(\theta(p(x)-c)+k_{d}\right)\right]\right\} .
$$

or equivalently

$$
\max _{x}\left\{D(x)(1-\theta)(p(x)-c)-k_{d}\right\}
$$

Substituting the expression for $p(x)$ from (7) and rearranging terms, the right-hand side of (8) is equivalent to:

$$
\max _{x}\left\{\frac{1-\theta}{1-\mu \theta} D(x)\left[x-c-\mu k_{p}-\left(\frac{1-\mu \theta}{1-\theta}\right) k_{d}\right]\right\} .
$$

\footnotetext{
${ }^{54}$ When $\left.k_{p}>\theta\left(p^{m}(c)-c\right)\right)$ then the left-hand side is decreasing in $k_{p}$.
} 
This is strictly positive (since $x$ is chosen to maximize profits); strictly decreasing in $k_{p}$ (by the envelope theorem); and smaller than $\Pi\left(p^{m}(c), c\right)$. Therefore an implicit solution $\widehat{k}_{p} \in\left(0, \theta\left(p^{m}(c)-c\right)\right)$ exists and is unique.

Now, let's turn to the comparative statics and show that $\widehat{k}_{p}$ is an increasing function of $\mu$. Let $x^{*}\left(k_{p}, \mu\right)$, which we write as $x^{*}$ for brevity, be the value of $x$ that maximizes (16). Then equation (8) defining $\widehat{k}_{p}$ may be written as:

$$
\Pi\left(c+\widehat{k}_{p} / \theta, c\right)=\frac{1-\theta}{1-\mu \theta} D\left(x^{*}\right)\left[x^{*}-c-\mu \widehat{k}_{p}-\left(\frac{1-\mu \theta}{1-\theta}\right) k_{d}\right],
$$

or, equivalently,

$$
\Pi\left(c+\widehat{k}_{p} / \theta, c\right)=\frac{1-\theta}{1-\mu \theta} D\left(x^{*}\right)\left[x^{*}-c-\mu \widehat{k}_{p}\right]-D\left(x^{*}\right) k_{d} .
$$

Totally differentiating with respect to $\widehat{k}_{p}$ and $\mu$ and rearranging terms gives: ${ }^{55}$

$$
\frac{d \Pi\left(c+\widehat{k}_{p} / \theta, c\right)}{d x} d \widehat{k}_{p} / \theta=-\frac{(1-\theta) \mu}{1-\theta} D\left(x^{*}\right) d \widehat{k}_{p}+\frac{1-\theta}{(1-\mu \theta)^{2}} D\left(x^{*}\right)\left[\theta\left(x^{*}-c\right)-\widehat{k}_{p}\right] d \mu .
$$

Moving the terms involving $d \widehat{k}_{p}$ to the left-hand side, this becomes

$$
\left[\frac{d \Pi\left(c+\widehat{k}_{p} / \theta, c\right)}{d x}(1 / \theta)+\frac{(1-\theta) \mu}{1-\theta} D\left(x^{*}\right)\right] d \widehat{k}_{p}=\left[\frac{1-\theta}{(1-\mu \theta)^{2}} D\left(x^{*}\right)\left(\theta\left(x^{*}-c\right)-\widehat{k}_{p}\right)\right] d \mu .
$$

Since $c+\widehat{k}_{p} / \theta<p^{m}(c)$, we know $d \Pi\left(c+\widehat{k}_{p} / \theta, c\right) / d x>0$ so the expression in brackets on the left-hand side is strictly positive. Now consider the right-hand side. Since $x^{*}$ maximizes (16), we have $x^{*}>p^{m}(c)>c+\widehat{k}_{p} / \theta$, and so $\theta\left(x^{*}-c\right)-\widehat{k}_{p}>$ $\theta\left(p^{m}(c)-c\right)-\widehat{k}_{p}>0$. So, the expression in brackets on the right-hand side is strictly positive, too. This concludes the proof that $\widehat{k}_{p}(\mu)$ is implicitly defined and $d \widehat{k}_{p} / d \mu>0$.

Proof of Proposition 1. Let's start with case 3. If the firms charge price $p^{m}(c)$ then consumers do not bring suit because $k_{p} \geq \theta\left(p^{m}(c)-c\right)$ and the aggregate profits are $\Pi\left(p^{m}(c), c\right)$. From (6) we know that other prices lead to lower profits.

Now, consider Case 2. Since $\left.k_{p} \in\left[\widehat{k}_{p}(\mu), \theta\left(p^{m}(c)-c\right)\right)\right)$, we have that $c+k_{p} / \theta \in$ $\left[c+\widehat{k}_{p}(\mu) / \theta, p^{m}(c)\right)$. Since consumers do not sue the firms when $p \leq c+k_{p} / \theta$ and

\footnotetext{
${ }^{55}$ Using the envelope theorem, we may disregard the effects of changes of $\widehat{k}_{p}$ and $\mu$ through $x^{*}$.
} 
profits are increasing in $p$ in this range, $p=c+k_{p} / \theta$ is the most profitable price that deters litigation. If the firm charge $p>c+k_{p} / \theta$ then consumers bring lawsuits. (8) implies that this would lead to lower aggregate profits.

Finally, consider Case 1. If $k_{p}<\widehat{k}_{p}(\mu)$ defined in Lemma 2 then the firms will raise the price to $p>c+k_{p} / \theta$ and accommodate lawsuits in equilibrium. Using (16) above, firm profits may be written as

$$
\left(\frac{1-\theta}{1-\mu \theta}\right) D(x)(x-c-\widetilde{k})
$$

where $\widetilde{k}=\mu k_{p}+\left(\frac{1-\mu \theta}{1-\theta}\right) k_{d}$, so $p^{m}(c+\widetilde{k})$ is the effective price that maximizes firm profits. This verifies firm profits in Case 1 of the proposition.

The comparative statics for Case 2 and Case 3 are immediate. Consider Case 1. Social welfare may be written $W\left(p^{m}(c+\widetilde{k}), c+k\right) .{ }^{56}$ An increase in $k_{p}$ will impact social welfare through both $k$ and $\widetilde{k}$. First, when $k_{p}$ rises, the litigation costs $k=k_{p}+k_{d}$ rise and social welfare falls. Second, when $k_{p}$ rises, $\widetilde{k}$ rises so $p^{m}(c+\widetilde{k})$ rises and social welfare falls. Now consider a change in $\mu$. An increase in $\mu$ may either increase or decrease social welfare: if $\frac{k_{p}}{k_{d}}<\frac{\theta}{1-\theta}$ then $\widetilde{k}$ falls and social welfare rises; if $\frac{k_{p}}{k_{d}}>\frac{\theta}{1-\theta}$ then $\widetilde{k}$ rises and social welfare falls. Now consider aggregate firm profits. Using (18) the aggregate profits may be written as

$$
\frac{1-\theta}{1-\mu \theta} D\left(p^{m}(\cdot)\right)\left[p^{m}(\cdot)-c-\mu k_{p}\right]-D\left(p^{m}(\cdot)\right) k_{d}
$$

where $p^{m}(\cdot)=p^{m}(c+\widetilde{k})$. We first consider a change in $k_{p}$. Holding $\mu \in(0,1]$ fixed, firm profits are a decreasing function of $k_{p}$. When $\mu=0$, firm profits do not depend on $k_{p}$. Now consider a change in $\mu$. Differentiating firm profits with respect to $\mu$, and applying the envelope theorem, the slope is

$$
\frac{1-\theta}{(1-\mu \theta)^{2}} D\left(p^{m}(\cdot)\right)\left[\theta\left(p^{m}(\cdot)-c\right)-k_{p}\right] \text {. }
$$

This is positive because $p^{m}(\cdot)>p^{m}(c)$ and $\theta\left(p^{m}(c)-c\right)-k_{p}>0$.

Proof of Corollary 2. We prove the corollary in three parts.

1. $k_{p}<\widehat{k}_{p}(0)$. Since $\widehat{k}_{p}^{\prime}(\mu)>0$ by Lemma 2 we have $k_{p}<\widehat{k}_{p}(\mu)$ for all $\mu \in(0,1]$. Proposition 1 establishes that firm profits are increasing in $\mu$, and social welfare is increasing in $\mu$ if and only if $\frac{k_{p}}{k_{d}}<\frac{\theta}{1-\theta}$.

\footnotetext{
${ }^{56}$ Note that social welfare depends on $\widetilde{k}$ only through its effect on the price, $p^{m}(c+\widetilde{k})$.
} 
2. $k_{p} \in\left[\widehat{k}_{p}(0), \widehat{k}_{p}(1)\right]$. Firm profits are a continuous function of $k_{p}$ and $\mu$, and Proposition 1 demonstrates that firm profits are increasing in $\mu$. So firm profits are maximized when $\mu=1$. Now consider social welfare. Suppose $\mu$ is sufficiently small so that $\widehat{k}_{p}(0) \leq \widehat{k}_{p}(\mu)<k_{p}<\widehat{k}_{p}(1)$. We are in part 2 of Proposition 1 and social welfare is $W\left(c+\frac{k_{p}}{\theta}, c\right)>W\left(p^{m}(c), c\right)$. If $\mu$ is larger so that $\widehat{k}_{p}(0) \leq k_{p}<\widehat{k}_{p}(\mu) \leq \widehat{k}_{p}(1)$ then we are in part 1 of Proposition 1 and social welfare is $W\left(p^{m}(c+\widetilde{k}), c+k\right)<W\left(p^{m}(c), c\right)$. Social welfare is maximized when $\mu$ satisfies $\widehat{k}_{p}(\mu)<k_{p}$. One solution is $\mu=0$.

3. $k_{p}>\widehat{k}_{p}(1)$. It follows that $k_{p}>\widehat{k}_{p}(\mu)$ for all $\mu \in[0,1)$. We are in part 3 of Proposition 1. Firms and society are indifferent about the value of $\mu$.

Proof of Proposition 2. We first show that there exists a unique $\bar{k}_{p}$ such that

$$
\Pi\left(c+\bar{k}_{p} / \theta, c\right)=\left(\frac{1-\theta}{1-\mu \theta}\right) \Pi\left(p^{m}(z), z\right),
$$

where $z=c+\left(\frac{1-\mu \theta}{1-\theta}\right) k_{d}$ and $\bar{k}_{p} \in\left(\widehat{k}_{p}(\mu), \theta\left(p^{m}(c)-c\right)\right)$ when $\mu \in(0,1]$ and $\bar{k}_{p}=\widehat{k}_{p}(\mu)$ when $\mu=0$.

Recall that the expression $\Pi\left(c+k_{p} / \theta, c\right)$ represents the firms' profits if they charge $p=c+k_{p} / \theta$ and litigation is deterred. This is a strictly increasing function of $k_{p}$ for all $k_{p} \in\left[0, \theta\left(p^{m}(c)-c\right)\right]$, equals zero if $k_{p}=0$, and equals $\Pi\left(p^{m}(c), c\right)$ when $k_{p}=\theta\left(p^{m}(c)-c\right)$. The right-hand side of the equality, $\left(\frac{1-\theta}{1-\mu \theta}\right) \Pi\left(p^{m}(z), z\right)$, represents the firms' profits when $k_{p}=0$ (but $k_{d} \geq 0$ ) and all lawsuits are brought (see Case 1 of Proposition 1). This is independent of $k_{p}$, is strictly positive (since we've assumed $k_{p}=0$ in defining $z$ ), and is strictly smaller than $\Pi\left(p^{m}(c), c\right)$ for all $k_{d}>0$. Therefore, there exists a unique $\bar{k}_{p}$, such that $\Pi\left(c+\frac{\bar{k}_{p}}{\theta}, c\right)=\left(\frac{1-\theta}{1-\mu \theta}\right) \Pi\left(p^{m}(z), z\right)$ where $z=$ $c+\left(\frac{1-\mu \theta}{1-\theta}\right) k_{d}$.

In terms of how $\bar{k}_{p}$ depends on $\mu$, first, note that when $\mu \in(0,1],\left(\frac{1-\theta}{1-\mu \theta}\right) \Pi\left(p^{m}(z), z\right)$ is strictly decreasing with respect to $k_{p}$ (per Lemma 2). Hence, $\left(\frac{1-\theta}{1-\mu \theta}\right) \Pi\left(p^{m}(z), z\right)>$ $\left(\frac{1-\theta}{1-\mu \theta}\right) \Pi\left(p^{m}\left(z+\mu \widehat{k}_{p}(\mu)\right), z+\mu \widehat{k}_{p}(\mu)\right)$. Given that $\widehat{k}_{p}(\mu)>0$ and that $\Pi\left(c+k_{p} / \theta, c\right)$ is strictly increasing with respect to $k_{p}$, we must have $\bar{k}_{p} \in\left(\widehat{k}_{p}(\mu), \theta\left(p^{m}(c)-c\right)\right)$. Second, when $\mu=0,\left(\frac{1-\theta}{1-\mu \theta}\right) \Pi\left(p^{m}(z), z\right)$ is independent with respect to $k_{p}$ and $\left(\frac{1-\theta}{1-\mu \theta}\right) \Pi\left(p^{m}(z), z\right)=\left(\frac{1-\theta}{1-\mu \theta}\right) \Pi\left(p^{m}\left(z+\mu \widehat{k}_{p}(0)\right), z+\mu \widehat{k}_{p}(0)\right)$. Hence, $\bar{k}_{p}=\widehat{k}_{p}(0)$. 
We will now define the threshold $\underline{k}_{p}$ in case 2 . Note that for $\left(\widehat{k}_{p}(\mu), \bar{k}_{p}\right)$ to be a nonempty set, we need $\mu \in(0,1]$. Given a value $k_{p} \in\left(\widehat{k}_{p}(\mu), \bar{k}_{p}\right)$, define $\underline{k}_{p} \in\left(0, \widehat{k}_{p}(\mu)\right)$, such that

$$
\Pi\left(c+k_{p} / \theta, c\right)=\left(\frac{1-\theta}{1-\mu \theta}\right) \Pi\left(p^{m}(y), y\right),
$$

where $y=c+\mu \underline{k}_{p}+\left(\frac{1-\mu \theta}{1-\theta}\right) k_{d}$. The left-hand side are the firm' profits if they charge $p=c+k_{p} / \theta$ and litigation is deterred. The left-hand side is positive, greater than $\Pi\left(c+\widehat{k}_{p}(\mu) / \theta, c\right)$, and does not depend on $\underline{k}_{p}$. The right-hand side represents the firms' profits if litigation is allowed (see Case 1 of Proposition 1). Since $y$ is an increasing function of $\underline{k}_{p}$, the right-hand side is a decreasing function of $\underline{k}_{p}$. When $\underline{k}_{p}=0$ then $y=z$ and the left-hand side is smaller than the right-hand side (since $\left.k_{p} \in\left(\widehat{k}_{p}(\mu), \bar{k}_{p}\right)\right)$. When $\underline{k}_{p}=\widehat{k}_{p}(\mu)$ then the left-hand side is larger than the righthand side. Therefore the threshold $\underline{k}_{p} \in\left(0, \widehat{k}_{p}(\mu)\right)$ exists and is unique. With $\bar{k}_{p}$ and $\underline{k}_{p}$ properly defined, let's turn to the three cases in the proposition.

First, consider Case 1, where $k_{p}<\widehat{k}_{p}(\mu)$. By definition, we get $k_{p}^{c}<k_{p}<\widehat{k}_{p}(\mu)$. From Case 1 of Proposition 1, we know that profits are (at least weakly) higher with $k_{p}^{c}$, while social welfare is strictly higher with $k_{p}^{c}$. Hence, when $\mu \in(0,1]$ firms have a strictly positive incentive to allow class actions and the social welfare is higher. When $\mu=0$, the firms are indifferent with respect to class action.

Now, consider Case 2, where $k_{p} \in\left[\widehat{k}_{p}(\mu), \bar{k}_{p}\right)$. Note that, we are assuming that $\mu \in(0,1]$. If $k_{p}^{c}>\underline{k}_{p}$, from above, firm profits are lower with class actions. So the firm will block class actions. From Proposition 1 , if $k_{p}^{c} \geq \widehat{k}_{p}(\mu)$, the firms' blocking class actions is socially inefficient. On the other hand, if $k_{p}^{c}<\widehat{k}_{p}(\mu)$, firms' blocking class actions is socially efficient. When $k_{p}^{c} \leq \underline{k}_{p}$ then firm profits are (at least weakly) higher with class actions and the firm will therefore allow class actions. From Proposition 1 and Corollary 1, we know that social welfare would be higher if class actions were blocked.

Finally, consider Case 3 , where $k_{p} \geq \bar{k}_{p}$. For any $k_{p}^{c}<k_{p}$, firm profits are lower with class actions (even if $k_{p}^{c}=0$ ). So the firms will block class actions. This is socially inefficient if $k_{p}^{c}>\widehat{k}_{p}(\mu)$. This is because social welfare is decreasing in $k_{p}^{c}$ when $k_{p}^{c} \in\left[\widehat{k}_{p}(\mu), \theta\left(p^{m}(c)-c\right)\right.$ ) (see Proposition 1 Case 2). Blocking class actions is socially efficient if $k_{p}^{c} \leq \widehat{k}_{p}(\mu)$.

Proof of Proposition 3. Lemma 2 establishes that $\widehat{k}_{p}(\mu)$ is increasing in $\mu$. Since $\mu(1-\gamma)<\mu$, we have $\widehat{k}_{p}(\mu(1-\gamma))<\widehat{k}_{p}(\mu)$. 
1. Suppose $k_{p}<\widehat{k}_{p}(\mu(1-\gamma))<\widehat{k}_{p}(\mu)$. We are in part 1 of Proposition 1 whether the firm allows or blocks class actions. Proposition 1 establishes that firm profits are increasing in $\mu$, and social welfare is increasing in $\mu$ if and only if $\frac{k_{p}}{k_{d}}<\frac{\theta}{1-\theta}$. So, the results about the private and social desirability of class actions in Proposition 3 follow immediately from the property that $\mu(1-\gamma)<\mu$.

2. Suppose $k_{p} \in\left[\widehat{k}_{p}(\mu(1-\gamma)), \widehat{k}_{p}(\mu)\right]$. If the firm blocks class actions, then we are in part 1 of Proposition 1 since $k_{p} \leq \widehat{k}_{p}(\mu)$. There is litigation in equilibrium and social welfare is $W\left(p^{m}(c+\widetilde{k}), c+k\right)<W\left(p^{m}(c), c\right)$. If the firm allows class actions, then we are in part 2 of Proposition 1 since $k_{p} \geq \widehat{k}_{p}(\mu(1-\gamma))$. The firm prices to deter litigation, and social welfare is $W\left(c+\frac{k_{p}}{\theta}, c\right)>W\left(p^{m}(c), c\right)$. So, social welfare is higher when class actions are allowed. The result that the firm will block actions follows from the property that firm profits are increasing in $\mu$ and the profit function is continuous.

3. When $k_{p}>\widehat{k}_{p}(\mu)$ then firms and society are indifferent about allowing and blocking class actions. 


\section{Online Appendix B}

This appendix contains formal propositions and proofs of the extensions discussed in Section 4.

Lemma 3. (Settlement Extension.) Aggregate firm profits may be written as a piecewise continuous function of the price, $p$ :

$$
\begin{cases}\Pi(p, c) & \text { if } p \leq c+k_{p} / \theta \\ \Pi(x(p), c)-(1-\mu) D(x(p)) s(p) & \text { if } p>c+k_{p} / \theta\end{cases}
$$

where $s(p)$ and $x(p)$ are defined in (11) and (12), respectively.

Proof of Lemma 3. When $p \leq c+k_{p} / \theta$ lawsuits are not brought and so aggregate profits are $D(p)(p-c)=\Pi(p, c)$. When $p>c+k_{p} / \theta$ cases are brought and are settled for $s(p)$. Firm profits are:

$$
\begin{gathered}
D(x(p))(p-c-s(p)) \\
=D(x(p))(p-\mu s(p)-c-(1-\mu) s(p)) \\
=D(x(p))(p-\mu s(p)-c)-(1-\mu) D(x(p)) s(p) .
\end{gathered}
$$

Substituting $x(p)=p-\mu s(p)$ from (12), profits are

$$
\begin{gathered}
D(x(p))(x(p)-c)-(1-\mu) D(x(p)) s(p) \\
=\Pi(x(p), c)-(1-\mu) D(x(p)) s(p) .
\end{gathered}
$$

Proposition 4. (Settlement Extension.) Suppose the consumers and the firms engage in Nash settlement bargaining under symmetric information with $\alpha \in[0,1]$ representing the firms' bargaining power. There exists a threshold $\widehat{k}_{p}^{s}(\mu) \in\left(0, \theta\left(p^{m}(c)-c\right)\right]$ with the following properties.

1. If $k_{p}<\widehat{k}_{p}^{s}(\mu)$ and $\mu \in[0,1]$, the effective price is $p^{m}\left(c+\widetilde{k}^{s}\right)$ where $\widetilde{k}^{s}=$ $\left(\frac{1-\mu}{1-\theta}\right)\left[(1-\alpha) k_{d}-\alpha k_{p}\right]$ and all cases settle in equilibrium. Aggregate firm profits are $\left(\frac{1-\theta}{1-\mu \theta}\right) \Pi\left(p^{m}\left(c+\widetilde{k}^{s}\right), c+\widetilde{k}^{s}\right)$ and social welfare is $W\left(p^{m}\left(c+\widetilde{k}^{s}\right), c\right)$. As $k_{p}$ increases, both firm profits and social welfare increase.

2. If $k_{p} \in\left[\widehat{k}_{p}^{s}(\mu), \theta\left(p^{m}(c)-c\right)\right)$ and $\mu \in[0,1)$, the price is $c+k_{p} / \theta$ and no lawsuits are brought in equilibrium. Aggregate firm profits are $\Pi\left(c+k_{p} / \theta, c\right)$ and social

B1 
welfare is $W\left(c+k_{p} / \theta, c\right)$. As $k_{p}$ increases, firm profits increase and social welfare decreases.

3. If $k_{p} \geq \theta\left(p^{m}(c)-c\right)$ and $\mu \in[0,1]$, the firms charge $p^{m}(c)$ and no lawsuits are brought in equilibrium. Aggregate firm profits are $\Pi\left(p^{m}(c), c\right)$ and social welfare is $W\left(p^{m}(c), c\right)$. Neither firm profits nor social welfare depend on $k_{p}$.

$\widehat{k}_{p}^{s}(\mu)$ has following properties: (1) $\widehat{k}_{p}^{s}(0) \in\left(0, \theta\left(p^{m}(c)-c\right)\right)$; (2) $d \widehat{k}_{p}^{s}(\mu) / d \mu>0$; and (3) $\widehat{k}_{p}^{s}(1)=\theta\left(p^{m}(c)-c\right)$.

Proof of Proposition 4. If $k_{p} \geq \theta\left(p^{m}(c)-c\right)$, then the firms can charge $p^{m}(c)$ without any threat of litigation. If $k_{p}<\theta\left(p^{m}(c)-c\right)$, then consumers would bring suit if the firms charge $p^{m}(c)$. Suppose the price is sufficiently high (i.e., $p>c+k_{p} / \theta$ ), so that the consumers have a credible threat to go to trial. The firms' aggregate profits are $D(x(p))(p-c-s(p))$ where $x(p)$ is defined in (12) above. Substituting for $s(p)$ from (11) above gives the firms' aggregate profits:

$$
D(x(p))\left[(1-\theta)(p-c)-k_{d}+\alpha\left(k_{p}+k_{d}\right)\right] .
$$

We will now replace $p-c$ in this profit function with a function that doesn't depend on $p$ directly and is linear in $x(p)-c$. Substituting (11) into (12) allows us to write:

$$
x(p)=p-\mu \theta(p-c)+\mu k_{p}-\mu(1-\alpha)\left(k_{p}+k_{d}\right),
$$

which becomes:

$$
\begin{gathered}
x(p)=(p-c)+c-\mu \theta(p-c)+\mu k_{p}-\mu(1-\alpha)\left(k_{p}+k_{d}\right), \\
x(p)=(1-\mu \theta)(p-c)+c-\mu\left[k_{d}-\alpha\left(k_{p}+k_{d}\right)\right], \\
(1-\mu \theta)(p-c)=x(p)-c+\mu\left[k_{d}-\alpha\left(k_{p}+k_{d}\right)\right] .
\end{gathered}
$$

Dividing by $1-\mu \theta$ allows us to write $p-c$ as a linear function of $x(p)-c$ :

$$
p-c=\left(\frac{1}{1-\mu \theta}\right)(x(p)-c)+\left(\frac{\mu}{1-\mu \theta}\right)\left[k_{d}-\alpha\left(k_{p}+k_{d}\right)\right] .
$$

We now replace $p-c$ in the firm's profit function above with this expression and get:

$$
\begin{gathered}
D(x(p))\left[\left(\frac{1-\theta}{1-\mu \theta}\right)(x(p)-c)+\left(\frac{(1-\theta) \mu}{1-\mu \theta}\right)\left[k_{d}-\alpha\left(k_{p}+k_{d}\right)\right]-\left(\frac{1-\mu \theta}{1-\mu \theta}\right)\left[k_{d}-\alpha\left(k_{p}+k_{d}\right)\right]\right] \\
=D(x(p))\left[\left(\frac{1-\theta}{1-\mu \theta}\right)(x(p)-c)-\left(\frac{1-\mu}{1-\mu \theta}\right)\left[k_{d}-\alpha\left(k_{p}+k_{d}\right)\right]\right] \\
=\left(\frac{1-\theta}{1-\mu \theta}\right) D(x(p))\left[x(p)-c-\left(\frac{1-\mu}{1-\theta}\right)\left(k_{d}-\alpha\left(k_{p}+k_{d}\right)\right)\right]
\end{gathered}
$$




$$
=\left(\frac{1-\theta}{1-\mu \theta}\right) D(x(p))\left(x(p)-c-\widetilde{k}^{s}\left(k_{p}, \mu\right)\right) .
$$

where

$$
\widetilde{k}^{s}\left(k_{p}, \mu\right)=\left(\frac{1-\mu}{1-\theta}\right)\left(k_{d}-\alpha\left(k_{p}+k_{d}\right)\right)
$$

To summarize, when $p>c+k_{p} / \theta$, then lawsuits are settled and the aggregate firm profits are $\left(\frac{1-\theta}{1-\mu \theta}\right) \Pi\left(x(p), c+\widetilde{k}^{s}\left(k_{p}, \mu\right)\right)$. If $p=c+k_{p} / \theta$, the firms deter lawsuits and earn profits of $\Pi\left(c+k_{p} / \theta, c\right)$.

Define $\widehat{k}_{p}^{s}$ to be the implicit solution to

$$
\Pi\left(c+k_{p} / \theta, c\right)=\max _{x}\left\{\left(\frac{1-\theta}{1-\mu \theta}\right) D(x)\left(x-c-\widetilde{k}^{s}\left(k_{p}, \mu\right)\right)\right\} .
$$

where $\widetilde{k}^{s}\left(k_{p}, \mu\right)$ is defined in $(25)$ above.

Claim 1. An implicit solution to equation $(26), \widehat{k}_{p}^{s} \in\left(0, \theta\left(p^{m}(c)-c\right)\right]$, exists and is unique.

Proof of Claim 1. Consider first the left-hand side of (26). When $k_{p}=0$, the left-hand side is equal to $\Pi(c, c)=0$, and when $k_{p}=\theta\left(p^{m}(c)-c\right)$ it is equal to $\Pi\left(p^{m}(c), c\right)$. Moreover, $\Pi\left(c+k_{p} / \theta, c\right)$ is a strictly increasing function of $k_{p}$ for all $k_{p} \in\left[c, \theta\left(p^{m}(c)-c\right)\right.$. Finally, regularity condition on the demand function, i.e., $D^{\prime \prime}(p)(p-c)+2 D^{\prime}(p)<0 \forall p$, implies that $\Pi\left(c+k_{p} / \theta, c\right)$ is a concave function of $k_{p}$.

Now consider the right-hand side of (26). First, note that since $\widetilde{k}^{s}\left(k_{p}, \mu\right)$ defined in (25) is a weakly decreasing function of $k_{p}$. Therefore, using the envelope theorem, the right-hand side of (26) is a continuous and weakly increasing function of $k_{p}$. Second, when $k_{p}=0$, the right-hand side is strictly positive (as it is for all $k_{p}$ ). Hence, when $k_{p}=0$, the right-hand side of (26) is strictly larger than the left-hand side.

We will now show that when $k_{p}=\theta\left(p^{m}(c)-c\right)$, the right-hand side is, at least weakly, smaller than the left-hand side. Note first that the left-hand side of (26) is independent of $\mu \forall k_{p} \in\left[0, \theta\left(p^{m}(c)-c\right)\right]$. Second, when $\mu=1$, (25) implies that $\tilde{k}^{s}\left(k_{p}, 1\right)=0$, so the right-hand side of $(26)$ equals $\max _{x}\{D(x)(x-c)\}=\Pi\left(p^{m}(c), c\right)$ $\forall k_{p}$. That is, when $\mu=1$, the right-hand side of (26) is equal to the left-hand side. Third, we now show that when $\mu<1$, the right-hand side of (26) is smaller than $\Pi\left(p^{m}(c), c\right)$. Differentiating the right-hand side of (26) with respect to $\mu$, and after some simplification, we get:

$$
\left(\frac{D\left(x^{*}\right)}{1-\mu \theta}\right)\left[\left(\frac{\theta(1-\theta)}{1-\mu \theta}\right)\left(x^{*}-c-\widetilde{k}^{s}\left(k_{p}, \mu\right)\right)+\left(k_{d}-\alpha\left(k_{p}+k_{d}\right)\right)\right],
$$

B3 
and substituting for $\widetilde{k}^{s}\left(k_{p}, \mu\right)$ from $(25)$ and combining terms gives

$$
=\left(\frac{1-\theta}{1-\mu \theta}\right) D\left(x^{*}\right)\left[\left(\frac{\theta}{1-\mu \theta}\right)\left(x^{*}-c\right)+\left(\frac{1}{1-\mu \theta}\right)\left(k_{d}-\alpha\left(k_{p}+k_{d}\right)\right)\right] \text {. }
$$

Substituting $x^{*}-c=(1-\mu \theta)\left(p^{*}-c\right)-\mu\left(k_{d}-\alpha\left(k_{p}+k_{d}\right)\right)$ from equation (24),

$$
\begin{gathered}
=\left(\frac{1-\theta}{1-\mu \theta}\right) D\left(x^{*}\right)\left[\theta\left(p^{*}-c\right)-\left(\frac{\mu \theta}{1-\mu \theta}\right)\left(k_{d}-\alpha\left(k_{p}+k_{d}\right)\right)+\left(\frac{1}{1-\mu \theta}\right)\left(k_{d}-\alpha\left(k_{p}+k_{d}\right)\right)\right] \\
=\left(\frac{1-\theta}{1-\mu \theta}\right) D\left(x^{*}\right)\left[\theta\left(p^{*}-c\right)+k_{d}-\alpha\left(k_{p}+k_{d}\right)\right],
\end{gathered}
$$

and using the formula for $s(p)$ from (11),

$$
=\left(\frac{1-\theta}{1-\mu \theta}\right) D\left(x^{*}\right) s\left(p^{*}\right) .
$$

Given that $s(p)>0$ whenever $\theta(p-c)>k_{p}$, which is the case for the right-hand side, this expression is strictly positive. Therefore, the right-hand side of (26) is a strictly increasing function of $\mu$. In sum, we have established existence of an implicit solution $\widehat{k}_{p}^{s}$ and that when $\mu=1$ that $\widehat{k}_{p}^{s}=\theta\left(p^{m}(c)-c\right)$ and when $\mu \in[0,1)$ that $\widehat{k}_{p}^{s} \in\left(0, \theta\left(p^{m}(c)-c\right)\right)$.

We have already shown that the left-hand side is an increasing and a concave function of $k_{p}$. We now show the right-hand side is an increasing and a convex function of $k_{p}$. Letting $x^{*}\left(k_{p}, \mu\right)$ be the effective price that maximizes the right-hand side of $(26)$. We may rewrite the right-hand side of (26) as

$$
\left(\frac{1-\theta}{1-\mu \theta}\right) D\left(x^{*}\left(k_{p}, \mu\right)\right)\left(x^{*}\left(k_{p}, \mu\right)-c-\widetilde{k}^{s}\left(k_{p}, \mu\right)\right) .
$$

Using the envelope theorem, the derivative of the right-hand side of (26) with respect to $k_{p}$ is

$$
-\left(\frac{1-\theta}{1-\mu \theta}\right) D\left(x^{*}\left(k_{p}, \mu\right)\right) \frac{d \tilde{k}^{s}\left(k_{p}, \mu\right)}{d k_{p}} .
$$

Using the expression for $\widetilde{k}^{s}\left(k_{p}, \mu\right)$ in $(25)$, this becomes

$$
-\left(\frac{1-\theta}{1-\mu \theta}\right) D\left(x^{*}\left(k_{p}, \mu\right)\right)\left(\frac{-\alpha(1-\mu)}{1-\theta}\right)=\left(\frac{\alpha(1-\mu)}{1-\mu \theta}\right) D\left(x^{*}\left(k_{p}, \mu\right)\right)>0
$$


and the second derivative is

$$
\left(\frac{\alpha(1-\mu)}{1-\mu \theta}\right) \frac{d D\left(x^{*}\left(k_{p}, \mu\right)\right)}{d x} \frac{d x^{*}\left(k_{p}, \mu\right)}{d k_{p}} .
$$

Note that $d D(\cdot) / d x<0$ because demand curves slope downwards and, from (25), we have $d x^{*}\left(k_{p}, \mu\right) / d k_{p}<0$. So the second derivative is positive. Therefore the righthand side of (26) is an increasing and convex function of $k_{p}$. Combining with the results that the right-hand side (1) is strictly positive when $k_{p}=0 ;(2)$ is strictly smaller than $\Pi\left(p^{m}(c), c\right)$ when $k_{p}=\theta\left(p^{m}(c)-c\right)$ and $\mu<1$; and (3) is increasing with respect to $k_{p}$, we have established uniqueness. Finally, given that the right-hand side is increasing with respect to $\mu$ while the left-hand side is independent of $\mu$, as $\mu$ increases, $\widehat{k}_{p}^{s}$ increases, and as shown before, when $\mu=1, \widehat{k}_{p}^{s}=\theta\left(p^{m}(c)-c\right)$ : the comparative statics is also established.

Before we proceed, we need to prove one more point: in case $k_{p}<\widehat{k}_{p}^{s}$, consumers will, in fact, have a credible litigation threat in equilibrium. Unlike the case without the possibility of settlement, this issue is not as straightforward since, when $\alpha$ is sufficiently close to 1 , for instance, we can have $\widetilde{k}^{s}<0$ and the firms can have an effective marginal cost that is lower than $c$, which, in turn, lowers $x^{*}$.

Claim 2. If $k_{p}<\widehat{k}_{p}^{s}$ defined in (26), and if the effective price is $p^{m}\left(c+\widetilde{k}^{s}\right)$ where $\widetilde{k}^{s}=\left(\frac{1-\mu}{1-\theta}\right)\left[(1-\alpha) k_{d}-\alpha k_{p}\right]$, then consumers have a credible threat to sue and all cases settle in equilibrium.

Proof of Claim 2. In this proof, we will do comparative statics on the parameters $k_{p}$ and $\alpha$ and will hold all of the other parameters constant. For a slight abuse of notation (since we're holding $\mu$ constant), let $\widehat{k}_{p}^{s}(\alpha)$ be the implicit solution to (26), expressed as a function of the parameter $\alpha$ (while holding all other parameters fixed). Let $x^{*}\left(k_{p}, \alpha\right)$ denote the effective price that maximizes the right-hand side of (26) and let $p^{*}\left(k_{p}, \alpha\right)$ be the corresponding actual price paid by consumers at the time of sale. Using the definitions of $s(p)$ and $x(p)$ in (11) and (12) we have:

$$
p=\frac{x(p)-\mu \theta c+\mu\left(k_{d}-\alpha\left(k_{p}+k_{d}\right)\right)}{1-\mu \theta},
$$

and so we have

$$
p^{*}\left(k_{p}, \alpha\right)=\frac{x^{*}\left(k_{p}, \alpha\right)-\mu \theta c+\mu\left(k_{d}-\alpha\left(k_{p}+k_{d}\right)\right)}{1-\mu \theta} .
$$

We will now proceed to prove that $p^{*}\left(k_{p}, \alpha\right)>c+k_{p} / \theta$ for all $k_{p}<\widehat{k}_{p}^{s}(\alpha)$. 
We will now prove that when $k_{p}=\widehat{k}_{p}^{s}(\alpha)$ and the effective price is $x^{*}\left(\widehat{k}_{p}^{s}(\alpha), \alpha\right)$ and the actual price is $p^{*}\left(\widehat{k}_{p}^{s}(\alpha), \alpha\right)$, then the consumers have a credible threat to sue: $p^{*}\left(\widehat{k}_{p}^{s}(\alpha), \alpha\right) \geq c+\widehat{k}_{p}^{s}(\alpha) / \theta$. We first prove this for $\alpha=1$, and then prove the result for all $\alpha$. Later, we will establish that the lawsuits are credible for all $k_{p}<\widehat{k}_{p}^{s}(\alpha)$ as well.

Consider first the special case where $\alpha=1$. It is not difficult to show that the firms' profit function in (13) is a continuous function of $p$ in this special case. Note that when $\alpha=1$ and $p=c+k_{p} / \theta$, then equation (11) gives $s(p)=0$ and equation (27) gives us $p=x(p)$. So, the firms' profits in (13) when $p$ approaches $c+k_{p} / \theta$ from below or above is equal to $\Pi(p, c)$. Recall that $x^{*}\left(\widehat{k}_{p}^{s}(1), 1\right)$ is the effective price that maximizes on the right-hand side of (26). The maximized profits on the right-hand side of (26) equal the profits on the left-hand side, $\Pi\left(c+\widehat{k}_{p}^{s}(1) / \theta, c\right)$. So $p^{*}\left(\widehat{k}_{p}^{s}(1), 1\right)=x^{*}\left(\widehat{k}_{p}^{s}(1), 1\right)=c+\widehat{k}_{p}^{s}(1) / \theta$. Therefore the plaintiff has a (weakly) credible threat to sue.

Now suppose $\alpha<1$. We will prove that when $k_{p}=\widehat{k}_{p}^{s}(\alpha)$, that the actual price $p^{*}\left(\widehat{k}_{p}^{s}(\alpha), \alpha\right)>c+\widehat{k}_{p}^{s}(\alpha) / \theta$ so the plaintiff has a credible threat to sue. First, we will prove that $p^{*}\left(k_{p}, \alpha\right)$ is a decreasing function of $\alpha$. Recall that $x^{*}\left(k_{p}, \alpha\right)=p^{m}\left(c+\widetilde{k}^{s}\right)$ where $\widetilde{k}^{s}=\left(\frac{1-\mu}{1-\theta}\right)\left[\left(k_{d}-\alpha\left(k_{p}+k_{d}\right)\right]\right.$. So holding $k_{p}$ fixed, an increase in the parameter $\alpha$ will lower the value of $\widetilde{k}^{s}$ and will decrease the firm's effective price. Therefore the effective price $x^{*}\left(k_{p}, \alpha\right)$ is an decreasing function of $\alpha$. Examination of equation (28) verifies that $p^{*}\left(k_{p}, \alpha\right)$ is a decreasing function of $\alpha$, too. ${ }^{57}$

Second, we will prove that $\widehat{k}_{p}^{s}(\alpha)<\widehat{k}_{p}^{s}(1)$ for all $\alpha<1$. To streamline the proof, define the function $\Psi\left(k_{p}, \alpha\right)$ be the maximized profits on the right-hand side of (26). Given the definition of $\widehat{k}_{p}^{s}(1)$, we have:

$$
\Pi\left(c+\widehat{k}_{p}^{s}(1) / \theta, c\right)=\Psi\left(\widehat{k}_{p}^{s}(1), 1\right) .
$$

Since $\widetilde{k}^{s}=\left(\frac{1-\mu}{1-\theta}\right)\left[k_{d}-\alpha\left(k_{p}+k_{d}\right)\right]$ is a decreasing function of $\alpha$, we know that the right-hand side of (26) is an increasing function of $\alpha$. So, holding $k_{p}$ fixed at $\widehat{k}_{p}^{s}(1)$, we have $\Psi\left(\widehat{k}_{p}^{s}(1), 1\right)>\Psi\left(\widehat{k}_{p}^{s}(1), \alpha\right)$. Next, since $\widetilde{k}^{s}=\left(\frac{1-\mu}{1-\theta}\right)\left[k_{d}-\alpha\left(k_{p}+k_{d}\right)\right]$ is a decreasing function of $k_{p}$, we have $\Psi\left(\widehat{k}_{p}^{s}(1), \alpha\right)>\Psi(0, \alpha)$. Finally, we know that

\footnotetext{
${ }^{57}$ Consider the right-hand side of equation (28). When $\alpha$ rises, $x^{*}\left(k_{p}, \alpha\right)$ falls and there is also a negative direct effect since $\alpha$ appears with a negative sign in the numerator. Therefore $p^{*}\left(k_{p}, \alpha\right)$ is a decreasing function of $\alpha$.
} 
$\Psi(0, \alpha)>0=\Pi(c+0 / \theta, c)$. Putting these expressions together, for all $\alpha<1$, we have:

$$
\Pi\left(c+\widehat{k}_{p}^{s}(1) / \theta, c\right)>\Psi\left(\widehat{k}_{p}^{s}(1), \alpha\right)>\Psi(0, \alpha)>\Pi(c+0 / \theta, c) .
$$

It follows that there is a fixed point, $\widehat{k}_{p}^{s}(\alpha) \in\left(0, \widehat{k}_{p}^{s}(1)\right)$, that satisfies $\Pi\left(c+\widehat{k}_{p}^{s}(\alpha) / \theta, c\right)=$ $\Psi\left(\widehat{k}_{p}^{s}(\alpha), \alpha\right)$.

To recap, we have established above that when $k_{p}=\widehat{k}_{p}^{s}(\alpha)$ and the effective price is $x^{*}\left(\widehat{k}_{p}^{s}(\alpha), \alpha\right)$ that the actual price $\left.p^{*}\left(\widehat{k}_{p}^{s}(\alpha), \alpha\right) \geq c+\widehat{k}_{p}^{s}(\alpha) / \theta\right)$ so consumers have a credible threat to sue. We will show that the threat to sue is also credible when $k_{p}<\widehat{k}_{p}^{s}(\alpha)$.

Recall that the effective price that maximizes the profit function on the right-hand side of $(26)$ is $x^{*}\left(k_{p}, \alpha\right)=p^{m}\left(c+\widetilde{k}^{s}\right)$ where $\widetilde{k}^{s}=\left(\frac{1-\mu}{1-\theta}\right)\left[k_{d}-\alpha\left(k_{p}+k_{d}\right)\right]$. Since $\widetilde{k}^{s}$ is a decreasing function of $k_{p}$ for all $\mu<1$ and $\alpha>0$, we know that the effective price $x^{*}\left(k_{p}, \alpha\right)$ is a decreasing function of $k_{p}$. To verify that the actual price $p^{*}\left(k_{p}, \alpha\right)$ is a decreasing function of $k_{p}$, consider the right-hand side of equation (28) above. When $k_{p}$ rises, the right-hand side falls for because $x^{*}\left(k_{p}, \alpha\right)$ falls and because $k_{p}$ appears with a negative sign. So, when $k_{p}<\widehat{k}_{p}^{s}(\alpha)$, the actual price is higher: $p^{*}\left(k_{p}, \alpha\right)>$ $p^{*}\left(\widehat{k}_{p}^{s}(\alpha), \alpha\right)$. Since $c+k_{p} / \theta<c+\widehat{k}_{p}^{s}(\alpha) / \theta$, the plaintiff has a credible threat to sue for all $k_{p}<\widehat{k}_{p}^{s}(\alpha)$.

In sum, we have shown that there exists a unique $\widehat{k}_{p}^{s}(\mu) \in\left(0, \theta\left(p^{m}(c)-c\right)\right]$, such that (1) when $k_{p}<\widehat{k}_{p}^{s}(\mu)$, firms allow litigation in equilibrium and charge the effective price of $p^{m}\left(c+\widetilde{k}^{s}\right) ;(2)$ when $k_{p} \in\left[\widehat{k}_{p}^{s}(\mu), \theta\left(p^{m}(c), c\right)\right)$, firms set the price equal to $c+k_{p} / \theta$ and disallow litigation in equilibrium; and (3) when $k_{p} \geq \theta\left(p^{m}(c)-c\right)$, firms charge $p^{m}(c)$, realize full monopoly profits, while no lawsuits are brought in equilibrium.

Proposition 5. (Fee Shifting Extension.) Suppose the loser in litigation must reimburse the winner's litigation costs. With $\mu=1$, when $\theta>\frac{k_{d}}{k_{p}+k_{d}}$, we get $\widehat{k}_{p}^{e r}(\mu)>$ $\widehat{k}_{p}(\mu)$, and when $\theta \leq \frac{k_{d}}{k_{p}+k_{d}}$, we get $\widehat{k}_{p}^{e r}(\mu) \leq \widehat{k}_{p}(\mu)$. With $\mu<1$, however, $\widehat{k}_{p}^{e r}(\mu) \gtreqless$ $\widehat{k}_{p}(\mu)$.

Proof of Proposition 5. From the expressions of $k_{p}^{e r}=(1-\theta)\left(k_{p}+k_{d}\right)$ and $k_{d}^{e r}=$ $\theta\left(k_{p}+k_{d}\right)$, it is clear that (1) when $\theta>\frac{k_{d}}{k_{p}+k_{d}}, k_{p}^{e r}<k_{p}$; (2) when $\theta<\frac{k_{d}}{k_{p}+k_{d}}, k_{p}^{e r}>k_{p}$; and (3) when $\theta=\frac{k_{d}}{k_{p}+k_{d}}, k_{p}^{e r}=k_{p}$.

Now, consider the equation (8). With the English Rule, in order to maximize the profit while keeping the litigation off the equilibrium, the firms will now have to set 
$\theta(p-c)=k_{p}^{e r}$. Hence, when $\theta>\frac{k_{d}}{k_{p}+k_{d}}$ and $k_{p}^{e r}<k_{p}$, the left-hand side of the equation (8) is larger. Conversely, when $\theta<\frac{k_{d}}{k_{p}+k_{d}}$ and $k_{p}^{e r}>k_{p}$, the left-hand side of the equation (8) is smaller.

Similarly, with the English Rule, it is easy to show that the maximized right-hand side of the equation (8) becomes:

$$
\Pi\left(x^{*}, c+k_{p}+k_{d}\right)-(1-\mu) D\left(x^{*}\right)\left[\theta\left(p\left(x^{*}\right)-c\right)-k_{p}^{e r}\right],
$$

where we used the expression $x^{*}$ to denote the argument that maximizes the righthand side of (8). From the expression, it is clear that, when $\mu=1$, because the second term disappears, the right-hand side is independent of the cost reimbursement rules. Hence, with $\mu=1$, when $\theta>\frac{k_{d}}{k_{p}+k_{d}}$, we get $\widehat{k}_{p}^{e r}(1)>\widehat{k}_{p}$; and when $\theta \leq \frac{k_{d}}{k_{p}+k_{d}}$ we get $\widehat{k}_{p}^{e r}(1) \leq \widehat{k}_{p}$.

On the other hand, when $\mu<1$, when $\theta>\frac{k_{d}}{k_{p}+k_{d}}$, the right hand size is smaller compared to the case without fee-shifting. Since both sides of equation (8) decrease, we get $\widehat{k}_{p}^{e r} \gtreqless \widehat{k}_{p}$. When $\theta \leq \frac{k_{d}}{k_{p}+k_{d}}$, both sides of equation (8) increase, thereby making it uncertain whether $\widehat{k}_{p}^{e r}$ is greater or smaller than $\widehat{k}_{p}$.

Proposition 6. (Damage Multipliers Extension.) If $\theta<1$, then $\widehat{k}_{p}(\mu)>0$; as $\theta$ increases, $\widehat{k}_{p}(\mu)$ increases when $\mu=1$ but may or may not increase when $\mu<1$. If $\theta \geq 1$, then $\widehat{k}_{p}(\mu)=0$; firms will set $p=\min \left\{p^{m}(c), c+k_{p} / \theta\right\}$, avoid litigation in equilibrium, and realize a strictly positive profit $\forall k_{p}>0$ and $\forall \mu \in[0,1]$.

Proof of Proposition 6. Suppose $\theta<1$ and consider the equation (8). When we differentiate the right-hand side with respect to $\theta$, with the envelope theorem, we get:

$$
-(1-\mu) D\left(x^{*}\right)\left[p\left(x^{*}, \theta\right)-c+\theta \frac{\partial p\left(x^{*}, \theta\right)}{\partial \theta}\right]
$$

and using the expression for $p(x)$ in $(7)$ this becomes

$-(1-\mu) D\left(x^{*}\right)\left[p\left(x^{*}, \theta\right)-c+\theta\left(\left(\frac{\mu}{1-\mu \theta}\right)^{2}\left(\theta\left(x^{*}-c\right)-k_{p}\right)+\left(\frac{\mu}{1-\mu \theta}\right)\left(x^{*}-c\right)\right)\right]$.

Note that when $\mu=1$, the expression is equal to zero: with $\mu=1$, the right-hand side does not change as $\theta$ changes. When $\mu<1$, on the other hand, since $x^{*}-c>0$ in equilibrium, the expression is strictly negative. For instance, when $\mu=0$, the expression becomes $-D\left(x^{*}\right)\left(p\left(x^{*}, \theta\right)-c\right)<0$. Hence, when $\mu<1$, the right-hand 
side decreases as $\theta$ increases: allowing litigation in equilibrium becomes less attractive as $\theta$ increases.

Now consider the left-hand side of (8). Since we know that when the firms are blocking litigation in equilibrium, the price $c+k_{p} / \theta$ is less than the full monopoly price, $p^{m}(c)$. Recall that the profit function $\Pi(p, c)$ is concave in price $p$. So raising $\theta$ lowers the price $c+k_{p} / \theta$, making it even further away from $p^{m}(c)$ and reducing firm profits. Therefore, the left-hand side of (8) decreases as $\theta$ increases.

Combining these two results, when $\mu=1$, while the right-hand side of the equation (8) stays constant, the left-hand side decreases, thereby increasing $\widehat{k}_{p}(1)$. In other words, when $\mu=1$, the firms become more willing to allow litigation in equilibrium. On the other hand, when $\mu<1$, both the right-hand side and the left-hand side of equation (8) decrease, thereby making it ambiguous whether $\widehat{k}_{p}(\mu)$ will increase or decrease.

Now suppose $\theta \geq 1$. If $p^{m}(c) \leq c+k_{p} / \theta$, the firms can charge $p^{m}(c)$ without the threat of litigation. So the case of interest is $p^{m}(c)>c+k_{p} / \theta$. Using equation (5), if the firms charge a price $p>c+k_{p} / \theta$, the firms' aggregate profits are

$$
D(x(p))\left((1-\theta)(p-c)-k_{d}\right)<0,
$$

since $\theta \geq 1$ and $k_{d}>0$. When $\theta \geq 1$, the firms will not allow litigation in equilibrium. Hence, the optimal strategy for the firms is to set $p=c+k_{p} / \theta$, avoid litigation in equilibrium, and realize a positive profit $\forall k_{p}>0$ and $\forall \mu \in[0,1]$.

Proposition 7. (Public Enforcement Extension.) Suppose $\sigma F<(1-\sigma \tau) \Pi\left(p^{m}(c), c\right)$, so that public enforcement by itself does not deter collusion. If private antitrust lawsuits are prohibited, the firms charge $p^{m}(c)$ and social welfare is $W\left(p^{m}(c), c\right) .{ }^{58}$ If private antitrust lawsuits are allowed, there exists a threshold $\widehat{k}_{p}^{g}(\mu ; \sigma, \tau) \in\left[0, \theta\left(p^{m}(c)-\right.\right.$ c)) with the following properties.

1. If $k_{p}<\widehat{k}_{p}^{g}(\mu ; \sigma, \tau)$, the effective price is $p^{m}\left(c+\widetilde{k}^{g}\right)$ where $\widetilde{k}^{g}=\sigma\left(\mu k_{p}+\right.$ $\left.\frac{1-\sigma \mu \theta}{1-\sigma(\tau+\theta)} k_{d}\right)$, private lawsuits are brought in equilibrium and social welfare is $W\left(p^{m}\left(c+\widetilde{k}^{g}\right), c+k\right)$.

2. If $k_{p} \in\left[\widehat{k}_{p}^{g}(\mu ; \sigma, \tau), \theta\left(p^{m}(c)-c\right)\right)$, the price is $p \in\left\{c, c+k_{p} / \theta\right\}$, no private lawsuits are brought, and social welfare is $W(p, c)$.

3. If $k_{p} \geq \theta\left(p^{m}(c)-c\right)$, the price is $p^{m}(c)$, no private lawsuits are brought, and social welfare is $W\left(p^{m}(c), c\right)$.

\footnotetext{
${ }^{58}$ We are assuming that the fine $F$ and the penalty $\tau$ are transfers and therefore welfare neutral.
} 
Proof of Proposition \%. The analysis follows the structure of the proof for Lemma 2 but with some variations. Foremost, suppose private enforcement actions are prohibited. In that case, when the firms collude with $p>c$, their aggregate profits are:

$$
\begin{gathered}
D(p)(p-c)-\sigma(\tau D(p)(p-c)+F) \\
=D(p)(1-\sigma \tau)(p-c)-\sigma F .
\end{gathered}
$$

With the assumption of $\left.\sigma F<(1-\sigma \tau) \Pi\left(p^{m}(c), c\right)\right)$, the aggregate profits are maximized when the firms set $p=p^{m}(c)$. In equilibrium, firms realize $D\left(p^{m}(c)\right)(1-$ $\sigma \tau)\left(p^{m}(c)-c\right)-\sigma F$ and the social welfare is $W\left(p^{m}(c), c\right)$.

Now, suppose private enforcement actions are allowed. As before, we need to consider two cases. First, if the firms were to collude with $p=c+k_{p} / \theta$, there would only be public enforcement against collusion. The firms' aggregate profits will be

$$
D(p)(1-\sigma \tau)(p-c)-\sigma F
$$

If the firms were to set $p>c+k_{p} / \theta$, on the other hand, consumers will bring suit ex post. The effective price paid by the consumers is given by:

$$
x(p)=p-\sigma \mu\left(\theta(p-c)-k_{p}\right)
$$

and the aggregate firm profits are given by:

$$
\begin{gathered}
D(x(p))\left(p-c-\sigma \tau(p-c)-\sigma\left(\theta(p-c)+k_{d}\right)\right)-\sigma F \\
=D(x(p))\left((1-\sigma(\tau+\theta))(p-c)-\sigma k_{d}\right)-\sigma F \\
=D(x(p))(x(p)-c-\sigma k)-\sigma(1-\mu) D(x(p))\left(\theta(p-c)-k_{p}\right)-\sigma(D(x(p)) \tau(p-c)+F) .
\end{gathered}
$$

From the second line, we see that when $\sigma(\tau+\theta)>1$, and by setting $p>c+k_{p} / \theta$, firms realize a negative profit. In this case, allowing private litigation is (weakly) dominated by deterring private litigation. This is equivalent to the result with damage multiplier (with $\theta>1$ ).

To rewrite the aggregate profit expression in terms of $x$, when we were to invert $x(p)=p-\sigma \mu\left(\theta(p-c)-k_{p}\right)$, we get:

$$
p(x)=x+\frac{\sigma \mu}{1-\sigma \mu \theta}\left(\theta(x-c)-k_{p}\right)
$$

When we use this expression to rewrite the firms' aggregate profit function (when 
$\left.p>c+k_{p} / \theta\right)$ becomes:

$$
\frac{1-\sigma(\tau+\theta)}{1-\sigma \mu \theta} D(x)\left(x-c-\sigma\left(\mu k_{p}+\frac{1-\sigma \mu \theta}{1-\sigma(\tau+\theta)} k_{d}\right)\right)-\sigma F .
$$

We can let $\widetilde{k}^{g}=\sigma\left(\mu k_{p}+\frac{1-\sigma \mu \theta}{1-\sigma(\tau+\theta)} k_{d}\right)$. Note that when $\tau=0, \sigma=1$, and $F=0$, the firms' function becomes $\frac{1-\theta}{1-\mu \theta} D(x)\left(x-c-\sigma\left(\mu k_{p}+\frac{1-\mu \theta}{1-\theta} k_{d}\right)\right)$, which is identical to the earlier case with no public enforcement. When the firms choose $x$ to maximize the aggregate profits, we get the equilibrium aggregate profits of:

$$
\frac{1-\sigma(\tau+\theta)}{1-\sigma \mu \theta} D\left(x^{*}\right)\left(x^{*}-c-\sigma\left(\mu k_{p}+\frac{1-\sigma \mu \theta}{1-\sigma(\tau+\theta)} k_{d}\right)\right)-\sigma F
$$

where $x^{*}=p^{m}\left(c+\widetilde{k}^{g}\right)$ stands for the maximand.

With these two profit functions, to show that there is a $\widehat{k}_{p}^{g}(\mu ; \sigma, \tau) \in\left[0, \theta\left(p^{m}(c)-c\right)\right)$, first consider the firms' aggregate profits when they set $p=c+k_{p} / \theta$ :

$$
\Pi\left(c+k_{p} / \theta, c\right)=D\left(c+k_{p} / \theta\right)(1-\sigma \tau)\left(k_{p} / \theta\right)-\sigma F
$$

Note first that when $k_{p} \in\left[0, \theta\left(p^{m}(c), c\right)\right]$, the profits are strictly increasing with respect to $k_{p}$. When $F>0, \exists k_{p}^{\prime}>0$, such that $D\left(c+k_{p} / \theta\right)(1-\sigma \tau)\left(k_{p} / \theta\right)-\sigma F \leq 0 \forall k_{p} \leq k_{p}^{\prime}$. Hence, when $k_{p} \in\left[0, k_{p}^{\prime}\right.$, firms will simply set $p=c$ and realize $\Pi(c, c)=0$. When $k_{p}=\theta\left(p^{m}(c)-c\right)$, on the other hand, the firms realize an expected aggregate profit of $D\left(p^{m}(c)\right)(1-\sigma \tau)\left(p^{m}(c)-c\right)-\sigma F$. With the assumption of $D\left(p^{m}(c)\right)(1-\sigma \tau)\left(p^{m}(c)-\right.$ $c)-\sigma F=(1-\sigma \tau) \Pi\left(p^{m}(c), c\right)>0$, we get $k_{p}^{\prime}<\theta\left(p^{m}(c)-c\right)$. Hence, when firms deter private litigation (by setting $p \in\left\{c, c+k_{p} / \theta\right\}$ ), their expected aggregate profits are equal to zero when $k_{p} \in\left[0, k_{p}^{\prime}\right]$ and are strictly increasing when $k_{p} \in\left(k_{p}^{\prime}, \theta\left(p^{m}(c), c\right)\right]$.

Now consider the firms' aggregate profits when they allow private actions $(p>c+$ $\left.k_{p} / \theta\right)$. From above, their aggregate profits are given by $\frac{1-\sigma(\tau+\theta)}{1-\sigma \mu \theta} D\left(x^{*}\right)\left(x^{*}-c-\widetilde{k}^{g}\right)-$ $\sigma F$, where $\widetilde{k}^{g}=\sigma\left(\mu k_{p}+\frac{1-\sigma \mu \theta}{1-\sigma(\tau+\theta)} k_{d}\right)$. Foremost, note that $\frac{\partial \widetilde{k}^{g}}{\partial k_{p}}>0$ and $\frac{\partial x^{*}}{\partial k_{p}}>0$. The aggregate profits are, therefore, decreasing as $k_{p}$ rises. Given that $\frac{\partial \widetilde{k}^{g}}{\partial \tau}>0$, a larger $\tau$ functions as an increase in marginal cost for the firms. When $k_{p}=0$, for any $x$, the aggregate profits become:

$$
\frac{1-\sigma(\tau+\theta)}{1-\sigma \mu \theta} D(x)\left(x-c-\mu \frac{1-\sigma \mu \theta}{1-\sigma(\tau+\theta)} k_{d}\right)-\sigma F .
$$

Note that when $F$ is sufficiently large or $\sigma(\tau+\theta) \geq 1$, this expression is (weakly)

B11 
negative $\forall x \geq 0$. If, on the other hand, when $F$ is sufficiently small and $\sigma(\tau+\theta)<1$, firms can realize a strictly positive profit when $k_{p}=0$ with $p>c$. Finally, given that $\frac{\partial \Pi\left(x^{*}\left(k_{p}\right)\right)}{\partial k_{p}}<0$, with a sufficiently high $k_{p}$, which may be less than $\theta\left(p^{m}(c), c\right)$, we can get $\Pi\left(x^{*}\left(k_{p}\right)\right) \leq 0$. In that case, firms will simply set $p=c$.

With these two aggregate profit expressions, it is clear that there exists a $k_{p}^{\prime \prime} \in$ $\left[0, \theta\left(p^{m}(c)-c\right)\right)$ where the two profits are equal to each other. Let $\widehat{k}_{p}^{g}(\mu ; \sigma, \tau)=\inf \left(k_{p}^{\prime \prime}\right)$. Given that $k_{p}^{\prime}>0$, there are three possibilities: $\widehat{k}_{p}^{g}(\mu ; \sigma, \tau)=0$ (which happens when $F$ is sufficiently large (but with $\sigma F<(1-\sigma \tau) \Pi\left(p^{m}(c), c\right)$ ) or when $\sigma(\tau+\theta)>1$ ); $\widehat{k}_{p}^{g}(\mu ; \sigma, \tau) \in\left(0, k_{p}^{\prime}\right)$; and $\widehat{k}_{p}^{g}(\mu ; \sigma, \tau) \in\left[k_{p}^{\prime}, \theta\left(p^{m}(c), c\right)\right)$.

When $k_{p}<\widehat{k}_{p}^{g}(\mu ; \sigma, \tau)$, firms allow private litigation in equilibrium. The social welfare is $W\left(p^{m}\left(c+\widetilde{k}^{g}\right), c+k\right)<W\left(p^{m}(c), c\right)$. Allowing private actions, therefore, reduce social welfare. Furthermore, as $\tau$ increases, $\widetilde{k}^{g}$ increases and both firm profits and $W\left(p^{m}\left(c+\widetilde{k}^{g}\right), c+k\right)$ decrease. When $k_{p} \geq \widehat{k}_{p}^{g}(\mu ; \sigma, \tau)$, they block litigation by setting $p \in\left\{c, c+k_{p} / \theta\right\}$. The social welfare is $W(p, c)>W\left(p^{m}(c), c\right)$. In this region, private actions complement public enforcement and increase social welfare. Note that the firms will set $p=c$ when $\widehat{k}_{p}^{g}(\mu ; \sigma, \tau) \leq k_{p}^{\prime}$ and $k_{p} \in\left[\widehat{k}_{p}^{g}(\mu ; \sigma, \tau), k_{p}^{\prime}\right)$. Finally, when $k_{p} \geq \theta\left(p^{m}(c)-c\right)$, firms set $p=p^{m}(c)$. The social welfare is $W\left(p^{m}(c), c\right)$ : private actions have no effect on social welfare.

Proposition 8. (Repeat Play Extension.) Consider an infinitely repeated pricing game where a firm that deviates from the collusive price is exempt from liability.

1. If $k_{p}<\widehat{k}_{p}(\mu)$ then the equilibrium in Proposition 1 is sustainable if and only if $r \leq\left[\frac{1-\mu \theta}{1-\theta} \frac{\Pi\left(p^{m}(c), c\right)}{\Pi\left(p^{m}(c+\widetilde{k}), c+\widetilde{k}\right)} N-1\right]^{-1}<\frac{1}{N-1}$.

2. If $k_{p} \geq \widehat{k}_{p}(\mu)$ then the equilibrium in Proposition 1 is sustainable if and only if $r \leq \frac{1}{N-1}$.

Proof of Proposition 8. We will construct conditions for which the outcome in Proposition 1 can be supported as a Nash equilibrium of a repeated pricing game. If all $N$ firms charge $p$ they divide the market equally; if firm $i$ deviates to a different price $p_{i}$, this is observed immediately by the cartel and there is Nash reversion where firms earn zero profits in the next round and every round thereafter.

1. Suppose $k_{p}>\widehat{k}_{p}(\mu)$. We are in case 2 or 3 of Proposition 1 where the firms set $p \leq c+k_{p} / \theta$ and there is no equilibrium litigation. As above, the most profitable deviation is $p_{i}=p-\varepsilon$ where $\varepsilon>0$ is arbitrarily small, and collusion is sustainable when $r \leq \frac{1}{N-1}$. 
2. Suppose $k_{p} \leq \widehat{k}_{p}(\mu)$. We are in case 1 of Proposition 1 where firms set $p>$ $c+k_{p} / \theta$ and there is equilibrium litigation. The effective price is $p^{m}(c+\widetilde{k})$ and denote aggregate cartel profits as $\widetilde{\Pi}=\frac{1-\theta}{1-\mu \theta} \Pi\left(p^{m}(c+\widetilde{k}), c+\widetilde{k}\right)<\Pi\left(p^{m}(c), c\right)$. If a firm deviated and charged an actual price $p_{i}$ slightly below the cartel's effective price, $p_{i}=p^{m}(c+\widetilde{k})-\varepsilon$, the firm would capture the entire market, and avoid all litigation, and have gross profits of $\Pi\left(p^{m}(c+\widetilde{k}), c\right)$. However, note that since the deviator's unit cost is $c$ (they are exempt from liability), the most profitable deviation is $p_{i}=p^{m}(c)<p^{m}(c+\widetilde{k})$ giving the deviating firm a gross profit of $\Pi\left(p^{m}(c), c\right)$. The firm will not deviate when the gain from deviating, $\Pi\left(p^{m}(c), c\right)-\frac{1}{N} \widetilde{\Pi}$ is smaller than the long run loss from Nash reversion, $\frac{1}{r N} \widetilde{\Pi}$. Collusion is sustainable when $r \leq\left[\frac{\Pi\left(p^{m}(c), c\right)}{\widetilde{\Pi}} N-1\right]^{-1}<\frac{1}{N-1}$. The last step follows from $\widetilde{\Pi}<\Pi\left(p^{m}(c), c\right)$.

Finally, the proof has assumed that a deviating firm is exempt from liability, but the case when a deviating firm is subject to liability is simpler. Suppose that a firm who deviates from the collusive agreement in Proposition 1 still faces liability for overcharges. It is easy to see that if the firms are sufficiently patient, $r \leq \frac{1}{N-1}$, the outcome in Proposition 1 is sustainable as an equilibrium of the repeated pricing game. ${ }^{59}$ Given that the effective price (under collusion), $x=p-\mu \times \max \{(1-\theta)(p-$ $\left.c)-k_{p}, 0\right\}$, is an increasing function of the actual price, the most profitable unilateral deviation is to undercut the actual price slightly and capture the entire market. ${ }^{60}$ Letting $\Pi>0$ denote the aggregate profits, the long-run loss from Nash reversion, $\left(\frac{1}{r N}\right) \Pi$, exceeds the short-run gain from deviating, $\Pi-\left(\frac{1}{N}\right) \Pi$, when $r \leq \frac{1}{N-1} \cdot{ }^{61}$

\footnotetext{
${ }^{59}$ In our simple model with homogeneous products and no capacity constraints, the threshold discount rate does not depend on the price $p$. In other settings, higher prices could make collusion harder for the firms. See for example Bos et al.'s (2018) elegant model of public enforcement.

${ }^{60}$ If a firm deviates to a slightly lower price $p_{i}<p$, then the effective price is lower as well, $x_{i}<x$.

${ }^{61} \mathrm{~A}$ similar argument demonstrates that collusion is totally deterred, and firms earn zero profits, when $r>\frac{1}{N-1}$.
} 